TITLE:

\title{
Non-linear transient behavior during soil liquefaction based on re-evaluation of seismic records
}

$\operatorname{AUTHOR}(S):$

Kamagata, S.; Takewaki, Izuru

\section{CITATION:}

Kamagata, S.... [et al]. Non-linear transient behavior during soil liquefaction based on reevaluation of seismic records. Soil Dynamics and Earthquake Engineering 2015, 71: 163184

ISSUE DATE:

2015-04

URL:

http://hdl.handle.net/2433/196054

\section{RIGHT:}

(c) 2015 Elsevier Ltd. NOTICE: this is the author's version of a work that was accepted for publication in Soil Dynamics and Earthquake Engineering. Changes resulting from the publishing process, such as peer review, editing, corrections, structural formatting, and other quality control mechanisms may not be reflected in this document. Changes may have been made to this work since it was submitted for publication. A definitive version was subsequently published in Soil Dynamics and Earthquake Engineering, 71, 2015, doi:10.1016/j.soildyn.2015.01.017; この論文は出版社版でありません 。引用の際には出版社版をご確認ご利用ください。; This is not the published version. Please cite only the published version. 


\title{
Non-linear Transient Behavior during Soil Liquefaction Based on Re-evaluation of Seismic Records
}

\author{
S. Kamagata ${ }^{1}$ and I. Takewaki ${ }^{2 *}$ \\ ${ }^{1}$ Nuclear Power Department, Kajima Corporation, Tokyo 107-8348, Japan \\ ${ }^{2}$ Dept of Architecture and Architectural Eng., Kyoto University, Kyoto 615-8540, Japan \\ *Corresponding author: takewaki@archi.kyoto-u.ac.jp
}

\begin{abstract}
Focusing on soil liquefaction, the seismic records during the Niigata-ken earthquake in 1964, the southern Hyogo prefecture earthquake in 1995 and the 2011 off the Pacific coast of Tohoku earthquake are analyzed by the non-stationary Fourier spectra. The shift of dominant frequency in the seismic record of Kawagishi-cho during the Niigata-ken earthquake is evaluated based on the time-variant property of dominant frequencies. The reduction ratio of the soil stiffness is evaluated from the shift ratio of dominant frequency. It is detected that the pulse wave in the transient process during the progressing liquefaction is composed of the primary mode and the secondary modes. Using the seismic records at the underground of Port Island during the southern Hyogo prefecture earthquake in 1995, the amplification of liquefaction is evaluated by comparing the maximum amplitude spectra of seismic records at GL 0m and GL-83m. The average shear strain of underground is calculated from the numerically integrated displacement profiles and the deterioration ratio of stiffness is evaluated from the G- $\gamma$ relation. The amplification of liquefaction at Chiba bay area is evaluated by using the ratio of the maximum amplitude spectra of CHB024 and CHBH10 (Borehole) from the mainshock and the aftershock of the 2011 off the Pacific coast of Tohoku earthquake.
\end{abstract}

Keywords: soil liquefaction, frequency-shift, pulse wave, cyclic mobility, non-stationary Fourier spectrum, maximum amplitude spectrum, frequency ratio of dominant components, deterioration ratio of soil stiffness 


\section{Introduction}

Earthquake engineering has piled up the countermeasures to mitigate the seismic hazard based on the investigation on the hazard aspects and the analysis of seismic records. The 2011 off the Pacific coast of Tohoku earthquake (Mw9.0) and the following tsunami caused severe hazards in wide areas of Japan. Many field investigations and analytical researches have been conducted by the public institutions and researchers [1-4].

In Japan three seismic hazards occurred every two years from 2007 and many seismic records with large acceleration were measured at the nuclear power plants close to the epicenter. Peculiar pulse waves were observed in the seismic records during the Niigata-ken Chuetsu-oki earthquake in 2007 and the Suruga-bay earthquake in 2009. These pulse waves were measured at the local points. The present authors have adopted the non-stationary Fourier spectra [5] and have detected the occurring mechanism of pulse waves, such as the non-linear interaction between a building and surrounding soil [6-8] and the local deformation at the underground [9]. The numerically integrated displacement profiles were evaluated in the deformation process of the underground and calculated the shear strain using the relative displacement at underground. The deterioration ratio of soil stiffness was certified by fitting it to the G- $\gamma$ relation [10].

In this paper, the seismic records including soil liquefaction are analyzed using the above analytical method. The historical hazard due to soil liquefaction in Japan occurred fifty years ago during the Niigata-ken earthquake $\left(\mathrm{M}_{\mathrm{JMA}}\right.$ 7.5) in 1964 [11, 12]. The typical hazards due to soil liquefaction, such as the uneven settlement and the upset of reinforced concrete buildings, were observed (see Fig.1). The shift of dominant frequency was detected in the non-stationary Fourier spectra of the seismic records and the softening ratio of underground soil was estimated.

Severe soil liquefaction hazard occurred twenty years ago at Port Island during the southern Hyogo prefecture earthquake in 1995 ( $\mathrm{M}_{\mathrm{JMA}}$ 7.3). The shear strain in the underground was calculated from the numerically integrated displacement profiles and the softening ratio of soil stiffness was evaluated by fitting it to the G- $\gamma$ relation.

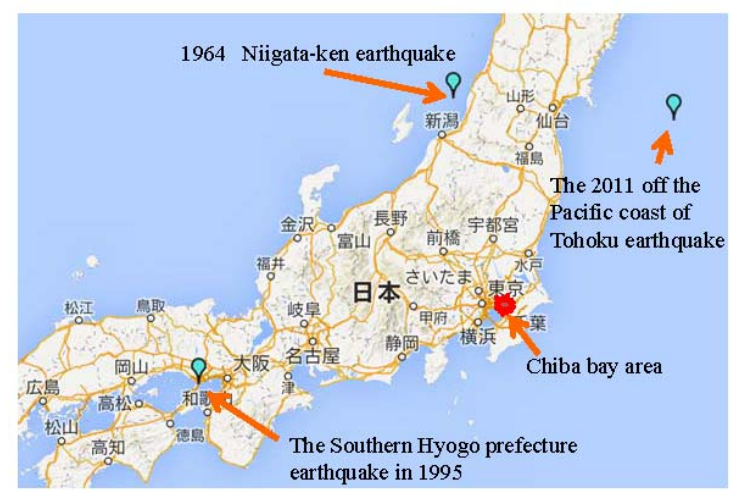

(http://www5.ocn.ne.jp/ botan/map_g.html)

Fig.1 Site map of earthquake events (http://www5.ocn.ne.jp/ botan/map_g.html) 
The 2011 off the Pacific coast of Tohoku earthquake caused the soil liquefaction hazard at Chiba bay area which is $350 \mathrm{~km}$ far from the epicenter. The pulse wave including cyclic mobility is analyzed by the non-stationary Fourier spectra and an secondary mode is detected as a result of occurring mechanisms of the pulse wave using the seismic records of CHB024 (K-NET) [13].

The novelties of this paper are (i) to apply the approach of the non-stationary Fourier spectra to soil liquefaction problems and make clear that the shift of dominant frequency is closely related to the transient process during soil liquefaction, (ii) to demonstrate that the shear strain in the underground calculated from the numerically integrated displacement profiles enables the computation of the softening ratio of soil stiffness during soil liquefaction and (iii) to show that the pulse wave including cyclic mobility consists of the primary and secondary modes.

\section{First seismic record of soil liquefaction (Kawagishi-cho)}

The first historical seismic records of soil liquefaction in Japan were measured during the Niigata-ken earthquake in 1964, in which an impressive seismic hazard occurred in a reinforced concrete building, such as the upset and the uneven settlement. The hazard seems to be caused by the sedimentary sand layer of the alluvium plain. This drastic seismic hazard in buildings and bridges were propagated in the world through the photographs and the seismic records, from which the researches were focused on the dynamical cyclic process of the liquefaction phenomenon [14-16]. In the fifty years after this seismic event, several seismic hazards due to soil liquefaction occurred and new findings were accumulated by many researchers [17-19].

\subsection{Analysis by non-stationary Fourier spectra}

Nonlinear interaction between a building and the surrounding soil has been focused in the previous research [5]. The pulse wave with the amplitude of $6.8 \mathrm{~m} / \mathrm{s}^{2}$ occurred at the Kashiwazaki-Kariwa nuclear power station during the Niigata-ken Chuetsu-oki earthquake in 2007 ( $\mathrm{M}_{\mathrm{JMA}}$ 6.8). The non-stationary Fourier spectra have been adopted to make clear the occurring mechanism of the pulse wave [5].

$$
F\left(\omega_{i} ; t_{j}\right)=\int_{-\infty}^{\infty} g\left(\tau, t_{j}\right) \exp \left[-i \omega_{i} \tau\right] d \tau
$$

where

$$
\begin{aligned}
& g\left(\tau, t_{j}\right)=\ddot{y}(\tau) ; t_{j}-t_{a} / 2 \leq \tau \leq t_{j}+t_{a} / 2 \\
& g\left(\tau, t_{j}\right)=0 ; \tau<t_{j}-t_{a} / 2, \quad t_{j}+t_{a} / 2<\tau \\
& t_{j}(j=1,2, \cdots M): j \text {-th time } \\
& \omega_{i}(i=1,2, \cdots N / 2): i \text {-th frequency } \\
& N ; \text { Number of steps in FFT analysis } \\
& M=T / \Delta T \quad ; \text { Step number of sweep } \\
& T ; \text { Duration of seismic record }
\end{aligned}
$$


$\Delta T$ : Sweep interval time

$t_{a}$; Width of data window (s)

$\ddot{y}(\tau)$; Seismic record

The soil liquefaction process can also be considered as a transient process related to the non-linear property of soil as well as the interaction between pore-pressure and bearing capacity of soil. The non-stationary Fourier spectra and the acceleration profiles of the seismic record at Kawagishi-cho during the Niigata-ken earthquake in 1964 are illustrated with the same horizontal axis in Fig.2. The contour level is normalized by the maximum value in the analysis range. The amplitude from 80 to $100 \%$ of the maximum value is red-colored, which detects the primary component of the seismic record. In order to evaluate the amplitude smaller than $30 \%$ of the maximum value, the partial region of time and frequency is analyzed as the partial view, in which the secondary components can be evaluated. In Fig.2, the partial view is analyzed to evaluate the higher mode in the frequency from $1 \mathrm{~Hz}$ to $5 \mathrm{~Hz}$ and in the time from $6.4 \mathrm{~s}$ to $10.4 \mathrm{~s}$.
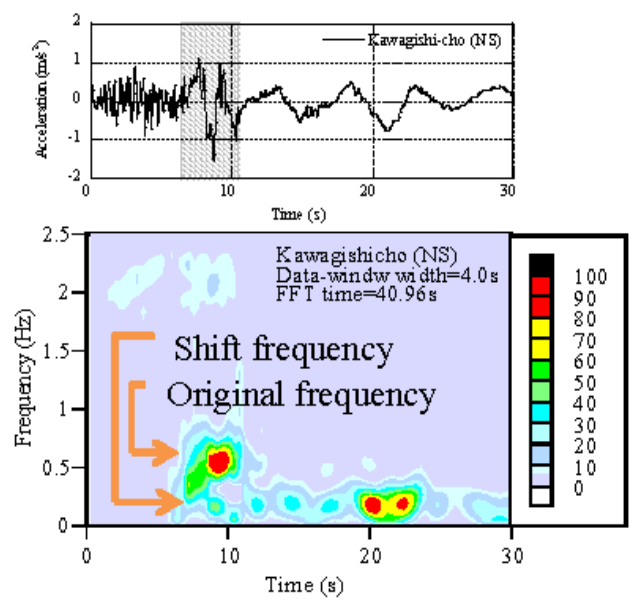

Global view (NS)
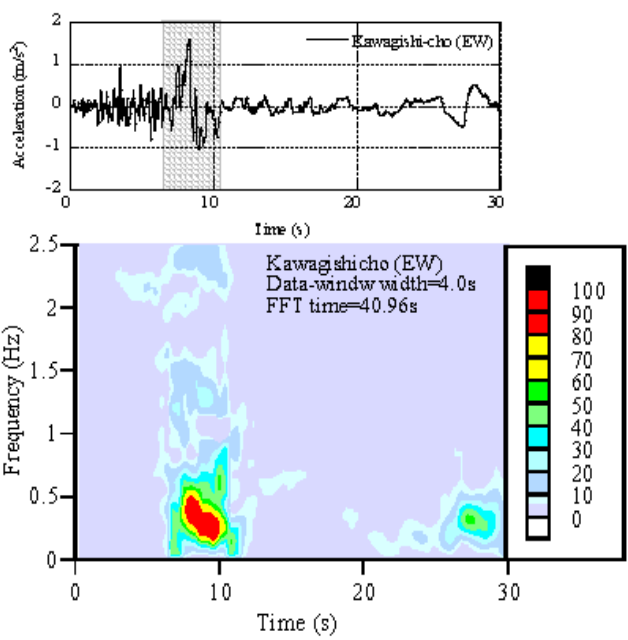

Global view (EW)
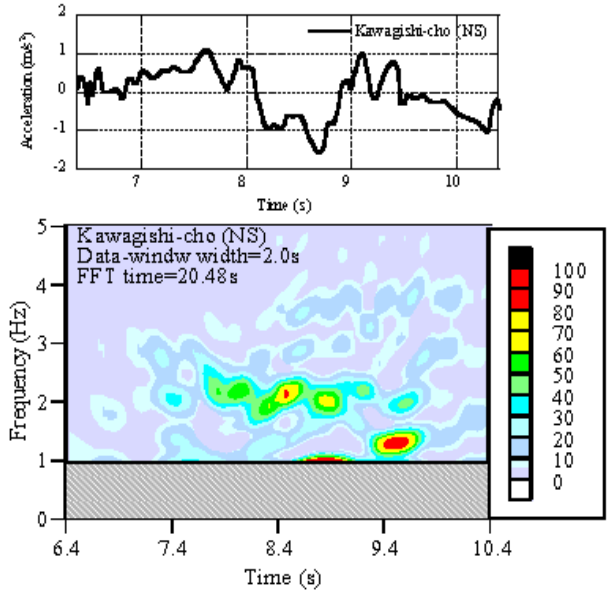

Partial view (NS)
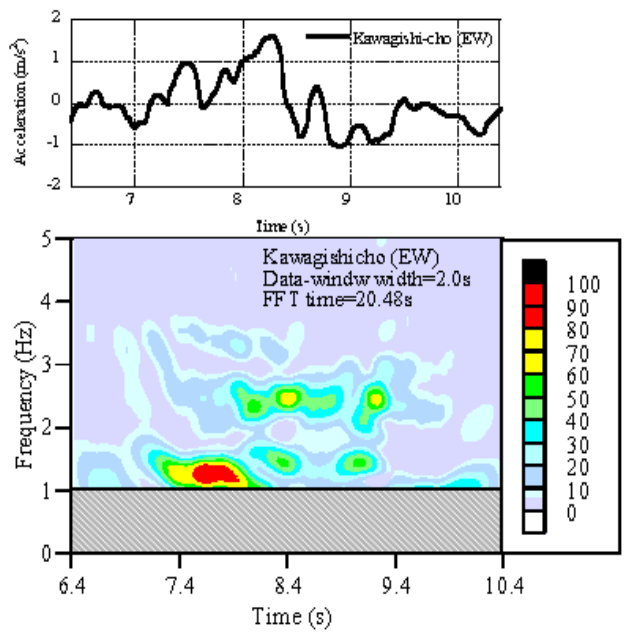

Partial view (EW)

Fig.2 Non-stationary Fourier spectra of primary mode of ground motion at Kawagishi-cho 
It can be seen that the dominant frequency of NS component shifted from $0.54 \mathrm{~Hz}$ to $0.17 \mathrm{~Hz}$ during 10s to 20s. The dominant components in EW component are scattered in the frequency range larger than $1.0 \mathrm{~Hz}$ around $8 \mathrm{~s}$ which are related to secondary modes. These properties are analyzed under different analysis conditions as shown in Table 1. The effect of data-window width, sampling frequency and sweeping interval time is analyzed in Appendix -1.

Table 1 Analysis condition

\begin{tabular}{|c|c|c|c|}
\hline Target & Data-window width & Sampling frequency & Sweep interval time \\
\hline Global view & 4s & $0.024 \mathrm{~Hz}$ & $0.4 \mathrm{~s}$ \\
\hline Partial view & 2s & $0.048 \mathrm{~Hz}$ & $0.04 \mathrm{~s}$ \\
\hline
\end{tabular}

Corresponding to the large amplitude of the acceleration profile, many frequency components are scattered in the frequency range larger than $2.0 \mathrm{~Hz}$. It may therefore be concluded that the maximum value of the acceleration profile is amplified by the secondary modes.

The maximum amplitude spectrum $F_{M A X}^{\text {Acc }}\left(\omega_{i}\right)$ is derived as a spectrum (maximum amplitude) by calculating the maximum value for $F^{\text {Acc }}\left(\omega_{i} ; t_{j}\right)$ in the duration time. The deterioration ratio of stiffness can be evaluated from the frequency ratio by Eq.(2).

Deterioration ratio of stiffness $=1.0-\left(f_{s} / f_{o}\right)^{2}$

where $f_{s}$; Secondary frequency, $f_{o}$; Original frequency

The maximum amplitude spectra in the global view and the partial view are illustrated in Fig.3, in which the maximum amplitude spectra of NS and EW components are illustrated in the same figure.

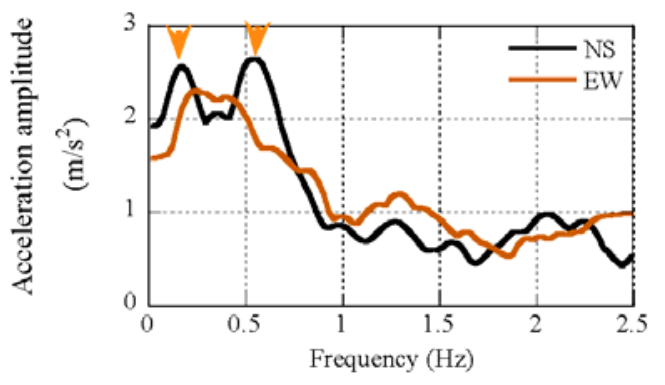

Primary mode

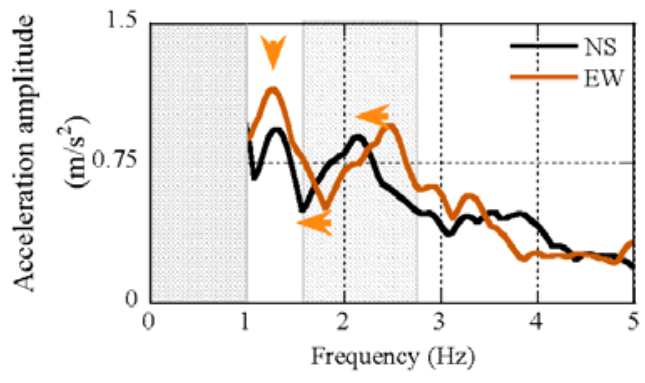

Additional mode

Fig.3 Maximum amplitude spectra of ground motion at Kawagishi-cho (1964)

The transient property of liquefaction can be summarized as follows.

(1) In the global view, two kinds of frequency shift are analyzed in the NS component. One is the hardening process from $0.35 \mathrm{~Hz}$ to $0.54 \mathrm{~Hz}$ during a short time from $7.2 \mathrm{~s}$ to $9.2 \mathrm{~s}$. The other is the softening process from $0.54 \mathrm{~Hz}$ to $0.17 \mathrm{~Hz}$ during a long time from $9.2 \mathrm{~s}$ to $20.4 \mathrm{~s}$.

(2) The frequency ratio of dominant components is 0.31 and the deterioration ratio of stiffness can 
be estimated to be $90 \%$.

(3) The dominant frequency of EW component shifted from $0.39 \mathrm{~Hz}$ to $0.24 \mathrm{~Hz}$ and the deterioration ratio of stiffness can be estimated to be $62 \%$.

(4) In the partial view, the dominant component of $1.3 \mathrm{~Hz}$ can be observed in NS and EW components. However the occurrence time of dominant component in NS component is 9.6s and that in EW component is 7.7s as shown in Fig.3.

(5) The secondary dominant frequency of NS component is $2.2 \mathrm{~Hz}$ and that of EW component is 2.5Hz. This difference of frequency-shift detects that the deterioration ratio of stiffness of NS component is $28 \%$ smaller than that of EW component.

In the transient process of soil liquefaction, the deterioration of soil is varied depending on the direction. This stiffness change is related to the re-construction of soil lattice, which is called the cyclic mobility.

\subsection{Analysis by numerically integrated displacement profiles}

Numerically integrated displacement profiles of NS and EW components are illustrated in Fig.4. The phase delay between EW and NS components enlarges to 0.9s during 5s to $15 \mathrm{~s}$.

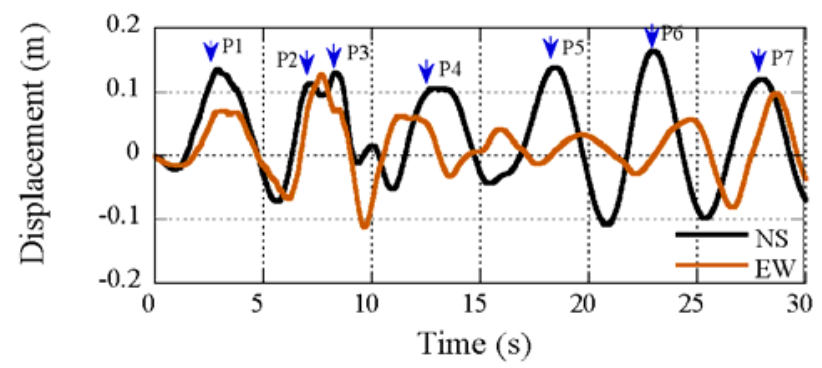

Fig.4 Displacement profile of ground motion at Kawagishi-cho (1964)

The duration time of 30s is subdivided into three sections and three orbits in the horizontal plane are illustrated with the site map in Fig.5. The direction of orbit plane is coincident with site-map.

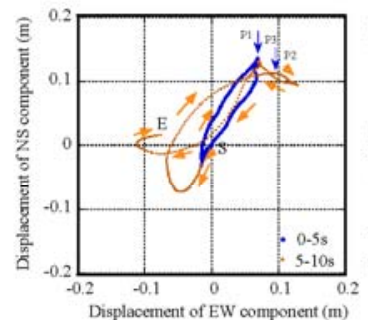

$0 \mathrm{~s}-10 \mathrm{~s}$

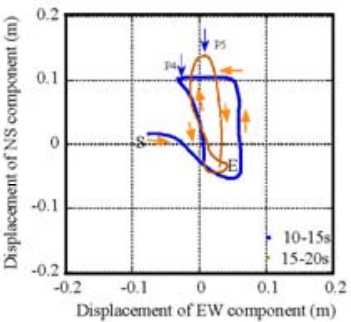

$10 \mathrm{~s}-20 \mathrm{~s}$

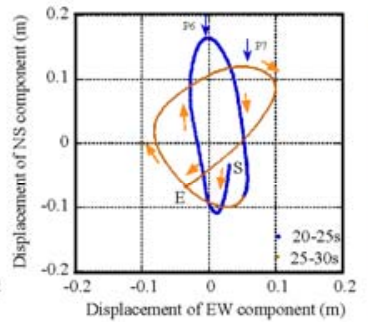

$20 \mathrm{~s}-30 \mathrm{~s}$

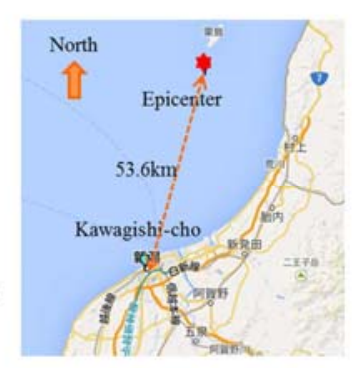

Fig.5 Orbit of displacement in horizontal plane 
At the first orbit from 0s to10s, the direction of movement during $0-5 \mathrm{~s}$ is coincident with the direction of wave propagation from the epicenter and the orthogonal movement occurs at $5 \mathrm{~s}$ and shifts to the elliptical orbit. At the second orbit from 10s to 20s, the principal axis of elliptical orbit shifts 45 degrees anti-clockwise and is close to the circular orbit. At the third orbit from 20s to 30s the amplitude of circular movement enlarges to $0.26 \mathrm{~m}$.

The displacement profile is illustrated together with the acceleration profiles in Fig.6. The displacement profile is analyzed by non-stationary Fourier spectra with data window width of $8 \mathrm{~s}$. The frequency range of global view is set from 0.0 to $1.0 \mathrm{~Hz}$ and that of partial view is set from 0.5 to $1.0 \mathrm{~Hz}$. The partial view is analyzed in the time from $4 \mathrm{~s}$ to $14 \mathrm{~s}$. The sweep interval time of global view is set $0.4 \mathrm{~s}$ and that of partial view is set $0.1 \mathrm{~s}$.

The vibration process of liquefaction can be summarized as follows.

(1) The pulse wave in the acceleration profile corresponds to the dual peak shape in the displacement profile.

(2) In the analytical result of the global view, the dominant components are scattered in the low frequency rang smaller than $0.4 \mathrm{~Hz}$.

(3) In the analytical result of the partial view, the frequency of dominant component changes from $0.5 \mathrm{~Hz}$ to $1.0 \mathrm{~Hz}$ during $8 \mathrm{~s}$ to $10 \mathrm{~s}$.

The dominant mode of NS component shifts from low frequency to high frequency, which can be explained as the re-construction of soil-lattice in the cyclic mobility phenomenon [12, 13].
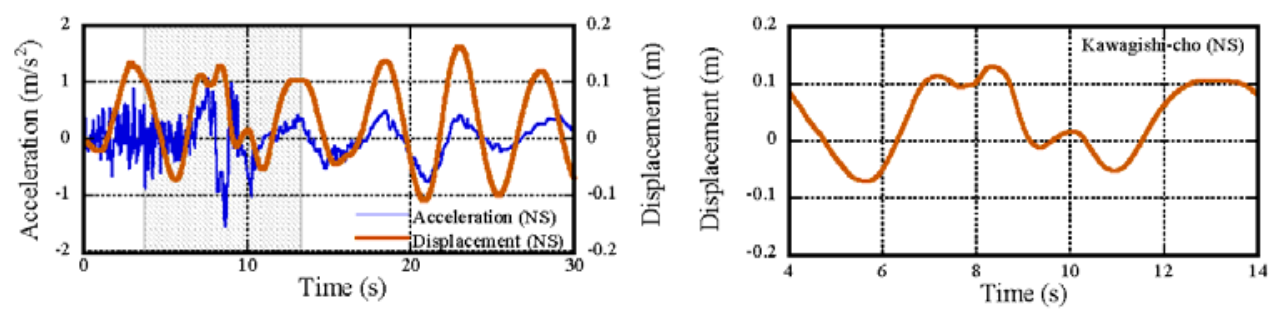

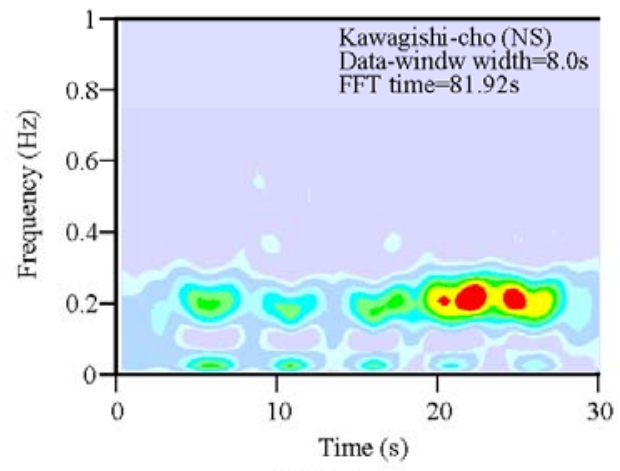

Global view

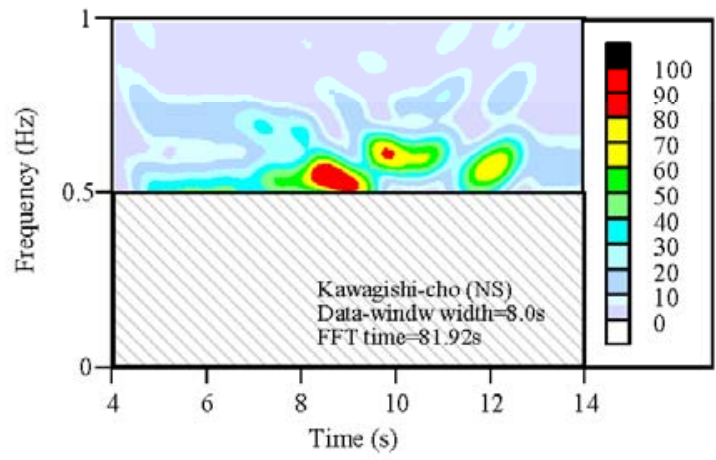

Partial view

Fig.6 Non-stationary Fourier spectra of displacement profiles (NS component) 


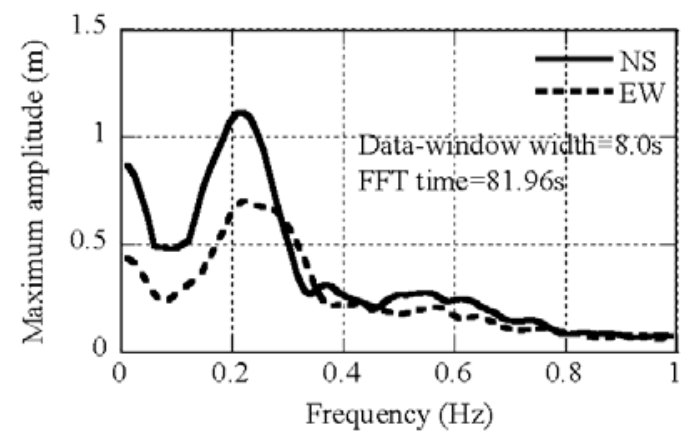

Global view

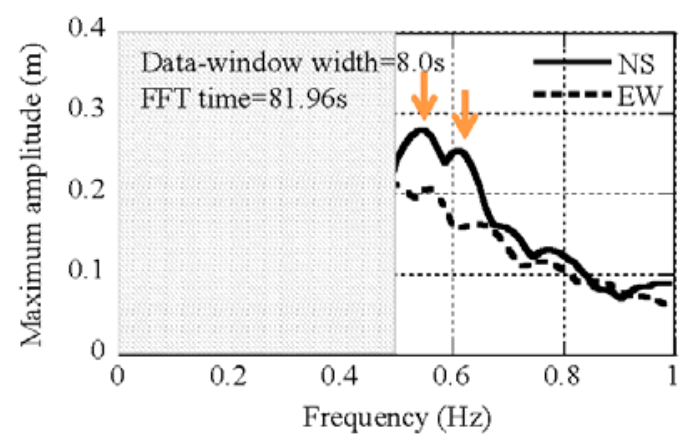

Partial view

Fig.7 Maximum amplitude spectra of displacement profiles

The maximum amplitude of $1.13 \mathrm{~m}$ occurs at $0.22 \mathrm{~Hz}$ (see Fig.7). In the partial view the dual peaks in the displacement profile are identified as dual components of $0.55 \mathrm{~Hz}$ and $0.61 \mathrm{~Hz}$ with the amplitude of $0.28 \mathrm{~m}$ and $0.25 \mathrm{~m}$, which is considered to be related to the cyclic mobility.

\section{Underground seismic records including soil liquefaction phenomenon (Port Island)}

In Japan the area of plain is $25 \%$ of the country and the remaining $75 \%$ is the area of mountain. Moreover $40 \%$ of plain is an alluvial plain spreading at the mouth of a river, in which $50 \%$ of the population and $75 \%$ of asset concentrate. To settle the shortage problem in usable land, the filling-up and the reclamation have been conducted at the bay area from 1600's (Edo period). These artificially developed lands have a possibility of soil liquefaction.
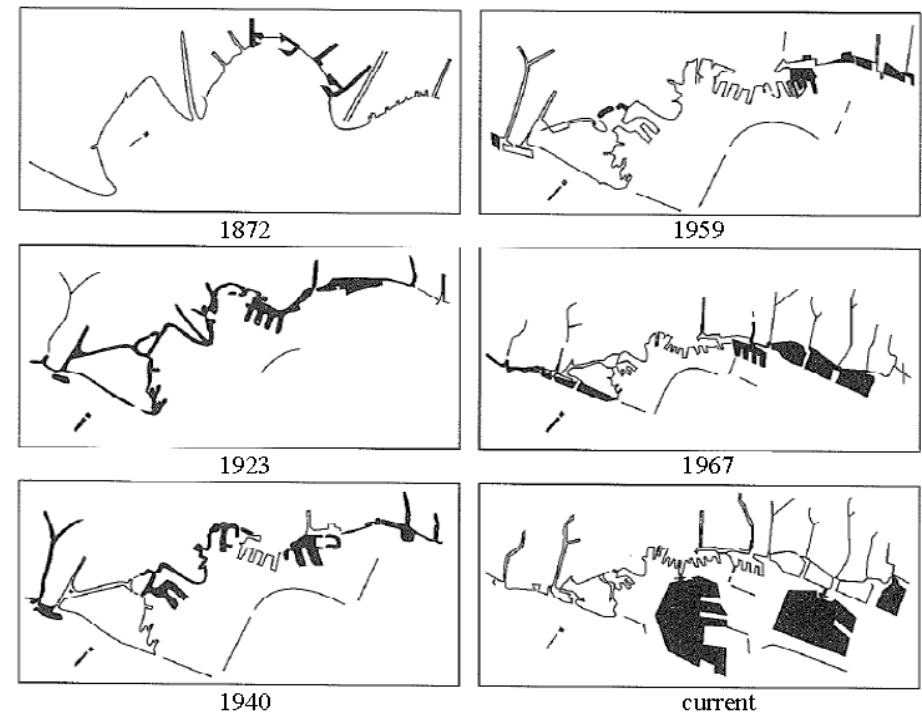

Fig.8 History of reclaimed land [20]

The Southern Hyogo prefecture earthquake in $1995\left(\mathrm{M}_{\mathrm{JAM}}\right.$ 7.2) shook the Kobe area and severe damages were caused in buildings and infra-structures. The soil liquefaction damage at Port Island is one of the typical hazards. The reclamation at Kobe bay area has continued from 1860's as shown in 
Fig.8. The Port and Harbor Research Institute (PHRI, re-established as Port and Airport Research Institute (PARI) in 2001) has arranged the accelerometers to evaluate the seismic behavior of underground from GL 0m to GL-83m (see Fig.9).

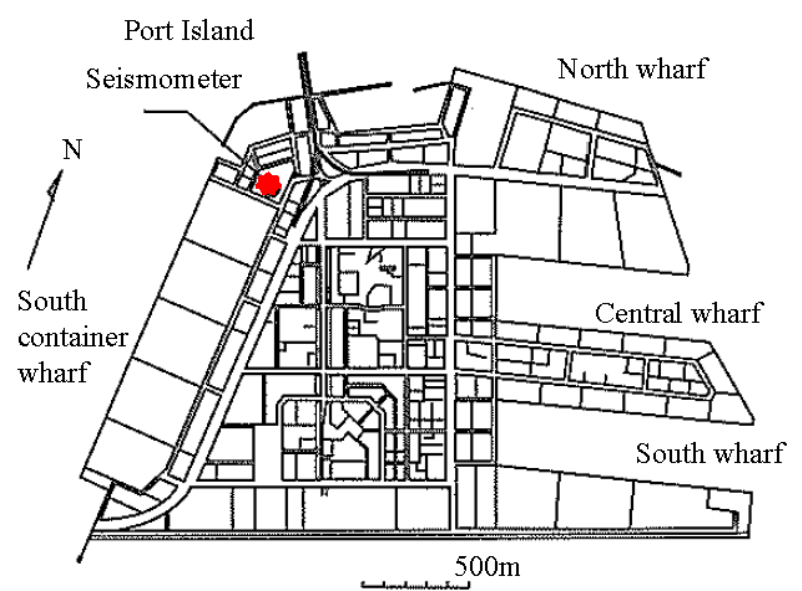

Fig.9 Measurement point [20]

In the reclamation work, many soil improvement methods, such as the sand-drain, the pre-loading and the vibration compaction, were adopted and their effects as the countermeasure of liquefaction were investigated to improve the efficiency of the mitigation method from the damage due to liquefaction hazard [20, 21]. The maximum acceleration of UD component is $7.9 \mathrm{~m} / \mathrm{s}^{2}$ at GL-16m. The profiles of the maximum value at the underground from GL 0m to GL-83m are illustrated in Fig.10. The soil property of the underground is illustrated in Fig.11. The depth of the filled layer is $20 \mathrm{~m}$ and the clay and sand layers exist in the underground from $-20 \mathrm{~m}$ to $-83 \mathrm{~m}$. The PHRI measured the velocity of shear wave before and after the earthquake in 1995 . The shear wave velocity of the filled layer became smaller after the earthquake, which is considered as a result of the softening of soil by the liquefaction.

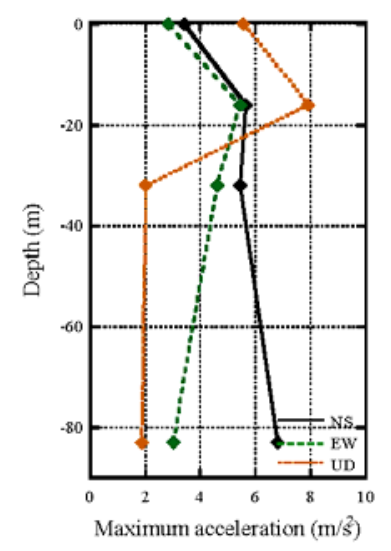

Fig.10 Maximum response [20]
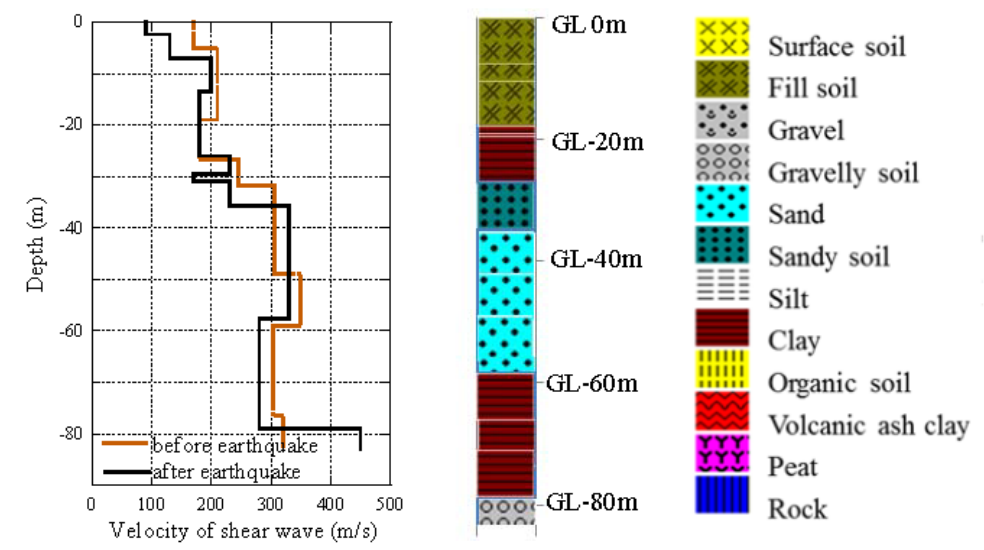
The maximum accelerations of seismic records are listed in Table 2. The amplification properties from GL-83m to GL 0m are different in NS, EW and UD components. In every component, the maximum accelerations at GL 0m are smaller than those of GL-16m.

Table 2 Maximum accelerations of seismic records $\left(\mathrm{m} / \mathrm{s}^{2}\right)[20]$

\begin{tabular}{|c|c|c|c|}
\hline & NS & EW & UD \\
\hline GL 0m & 3.41 & 2.84 & 5.56 \\
\hline GL-16m & 5.645 & 5.43 & 7.90 \\
\hline GL-32m & 5.44 & 4.62 & 2.00 \\
\hline GL-83m & 6.79 & 3.03 & 1.87 \\
\hline
\end{tabular}

The acceleration profiles at GL 0m, GL-16m, GL-32m and GL-83m are compared in Fig.12. The maximum values of NS components occur between 4 and 6 s (shaded in figure).
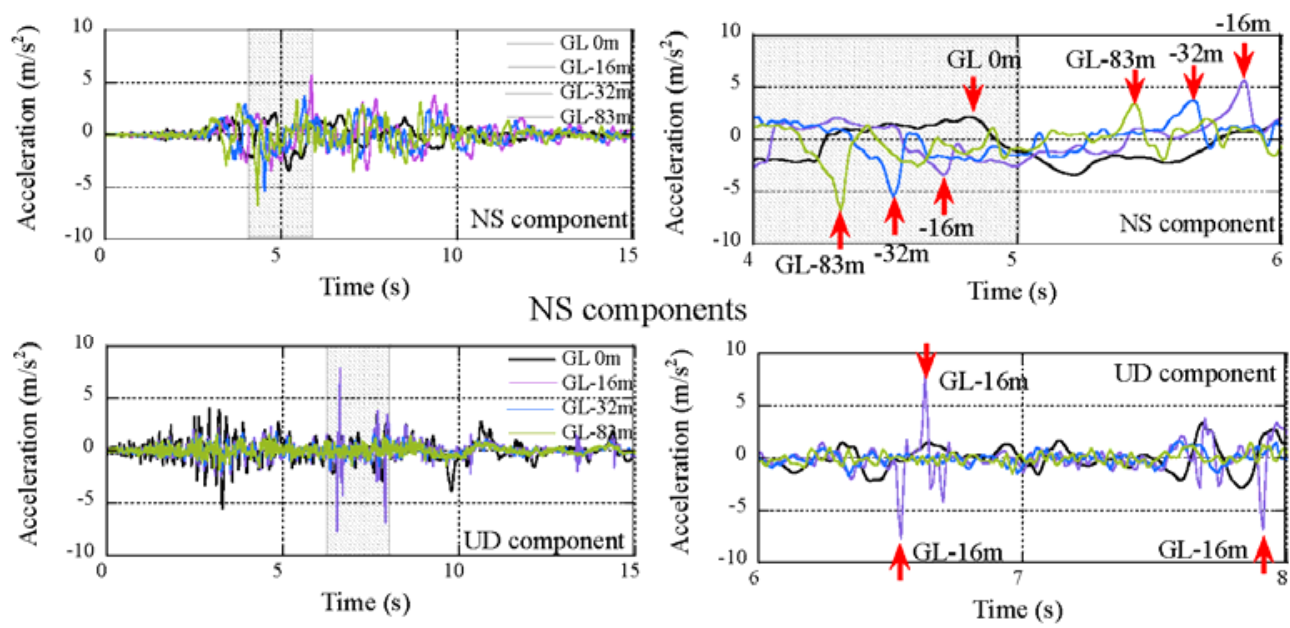

UD components

Fig.12 Comparison of acceleration profiles at four ground levels

The occurring time of peak values at NS component is delayed as closer to the surface from GL-83m (4.33s) to GL-16m (4.70s). The time delay is caused by the upward propagation of shear wave. No pulse wave occurs at the acceleration profile of GL $0 \mathrm{~m}$. The isolated pulse waves of UD component occur during 6 to $8 \mathrm{~s}$ (shaded in figure). The pulse waves occur only at the GL-16m. The occurring mechanism of the pulse wave may be due to the local deformation at the boundary of the filled layer at GL-20m as can be seen in soil conditions (see Fig.11).

\subsection{Analysis by non-stationary Fourier spectra}

The non-stationary Fourier spectra of all measured seismic records are illustrated together with the acceleration profile in Figs.13 and 14. The property of NS components is analyzed below. 
(1) The dominant components at GL-83m scatter in the frequency below 5.0Hz.

(2) The dominant components at GL-16m and GL $0 \mathrm{~m}$ shift from $1.0 \mathrm{~Hz}$ to $0.5 \mathrm{~Hz}$ at $5 \mathrm{~s}$.

The property of UD component can be analyzed as follows.

(3) The dominant component at GL-83m occurs at the frequency of $0.4 \mathrm{~Hz}$ and at the time of $10 \mathrm{~s}$.

(4) The pulse wave at GL-16m at the time of 7s is composed of many frequency components below $5.0 \mathrm{~Hz}$.

(5) The frequency of dominant component at GL $0 \mathrm{~m}$ and GL-16m shifts from $4.2 \mathrm{~Hz}$ to $0.5 \mathrm{~Hz}$.
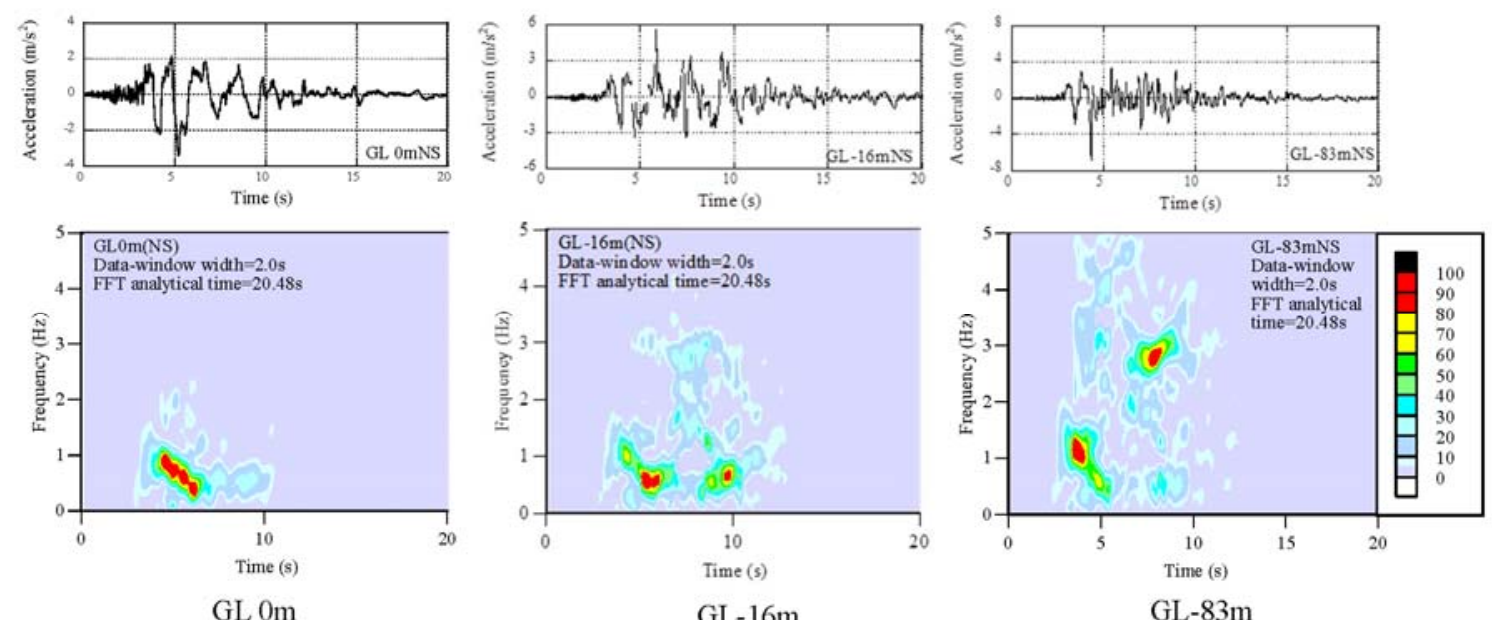

Fig.13 Non-stationary Fourier spectra of NS component
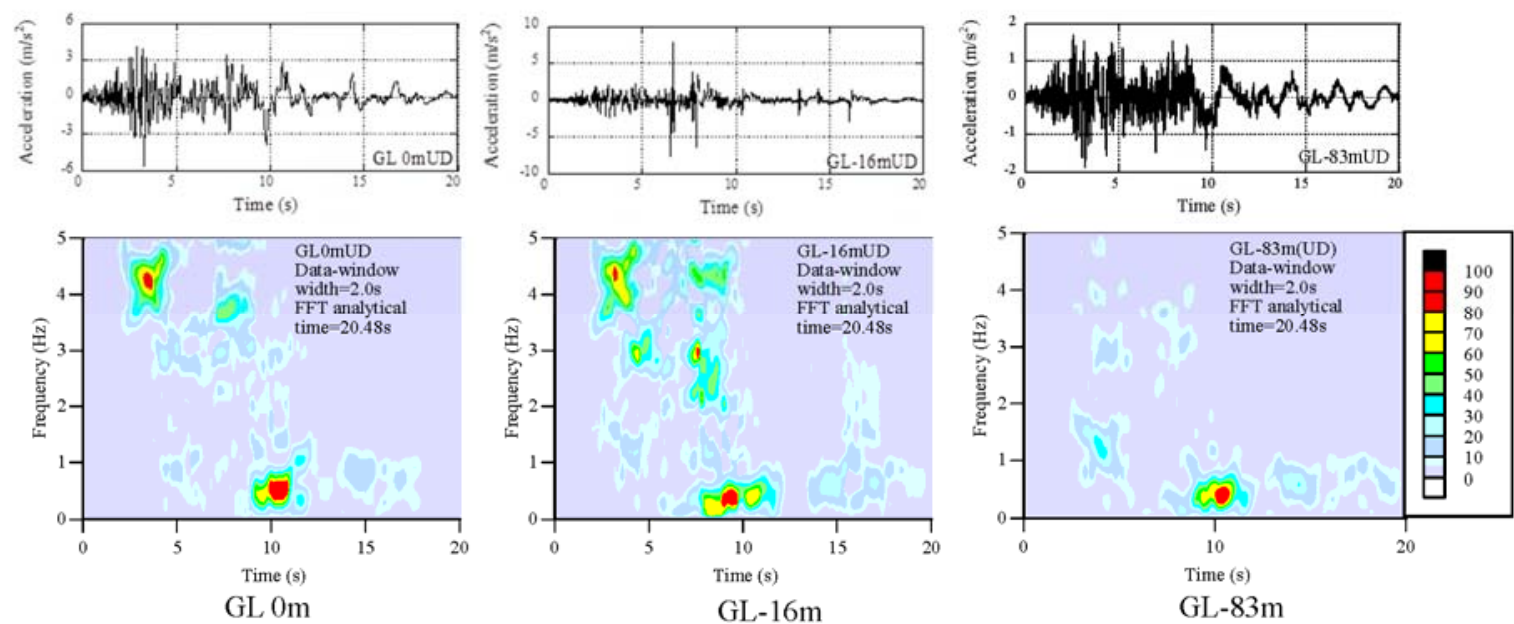

Fig.14 Non-stationary Fourier spectra of UD component

The maximum amplitude spectra are illustrated in Fig.15. The property of maximum amplitude can be analyzed as follows.

(1) The maximum amplitude of NS components increases to closer to the surface in the frequency range smaller than $1.1 \mathrm{~Hz}$. 
(2) The maximum amplitude of NS components decreases to closer to the surface in the frequency range larger than $1.1 \mathrm{~Hz}$.

(3) The maximum amplitude of NS component at GL $0 \mathrm{~m}$ exceeds $4.0 \mathrm{~m} / \mathrm{s}^{2}$ and multi-peaks appear from $0.88 \mathrm{~Hz}$ to $0.35 \mathrm{~Hz}$, which corresponds to the frequency-shift in the non-stationary Fourier spectra.

(4) The deterioration ratio of soil stiffness is estimated to be $85 \%$ from the frequency ratio of the beginning and the ending in the liquefaction process.

(5) The maximum amplitude of UD component at GL $0 \mathrm{~m}$ exceeds $3.0 \mathrm{~m} / \mathrm{s}^{2}$ at $0.4 \mathrm{~Hz}$ and $4.2 \mathrm{~Hz}$.

(6) The frequency component of $0.4 \mathrm{~Hz}$ is amplified in the surface from GL-16m to GL $0 \mathrm{~m}$.

(7) The frequency component of $4.2 \mathrm{~Hz}$ is gradually amplified in the underground from GL-83m to GL 0m.

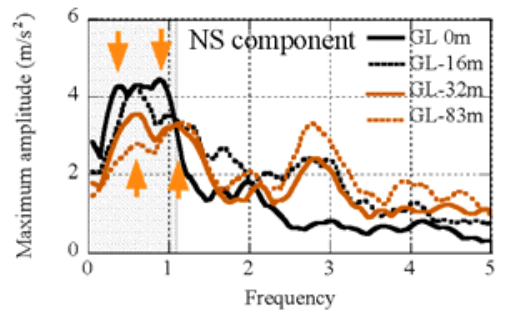

NS component

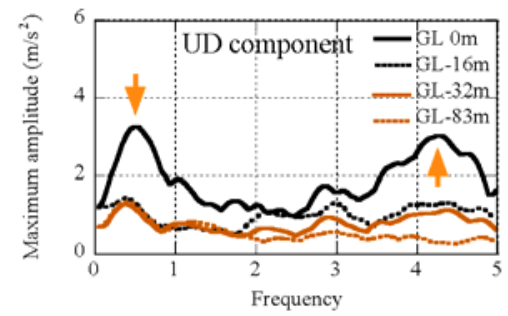

UD component

Fig.15 Comparison of maximum amplitude spectra

The amplification ratio of the maximum amplitude at GL 0m, GL-16m and GL-32m is evaluated by the comparison of the maximum amplitude at GL-83m (see Fig.16). The amplification ratio spectrum can be smoothed by the Hanning window operation (five repetitions).

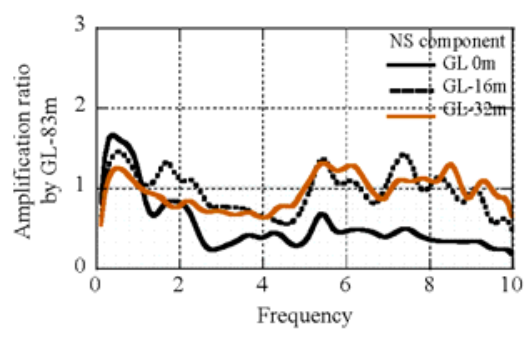

NS component

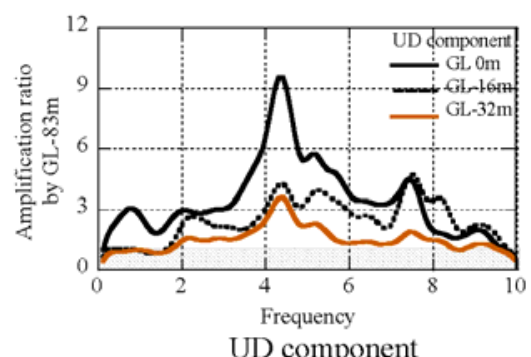

UD component

Fig.16 Comparison of amplification ratio spectra

The amplification ratio of NS components can be analyzed as follows.

(1) The amplification ratio at GL $0 \mathrm{~m}$ exceeds 1.0 in the frequency smaller than $2.0 \mathrm{~Hz}$ and is smaller than 1.0 in the frequency larger than $2.0 \mathrm{~Hz}$.

(2) The profiles of amplification ratio spectra at GL-16m and GL-32m do not differ much, which means that the soil layer from GL-16m to $-32 m$ vibrates with a uniform mode.

The amplification ratio of UD component can be analyzed as follows. 
(3) The amplification ratio at GL-32m, GL-16m and GL 0m is larger than 1.0 and increases toward the ground surface.

(4) The amplitude ratio at GL 0m is larger than 3.0 in the frequency range from $2.0 \mathrm{~Hz}$ to $8.0 \mathrm{~Hz}$ and the maximum value at GL $0 \mathrm{~m}$ value is 9.5 at $4.3 \mathrm{~Hz}$.

(5) The amplification of UD component is larger than that of NS and EW components.

The pulse waves of NS component at GL-16m and GL-83m occur with the interval time of 0.37s and the shape of the pulse wave is composed of a gradually increasing process and an abruptly decreasing process as shown in Fig.17. The pulse wave of UD component occurs in the form of a sharp one-sided shape at GL-16m. The property of pulse wave can be analyzed by the non-stationary Fourier spectra. The analysis conditions are listed in Table 3.
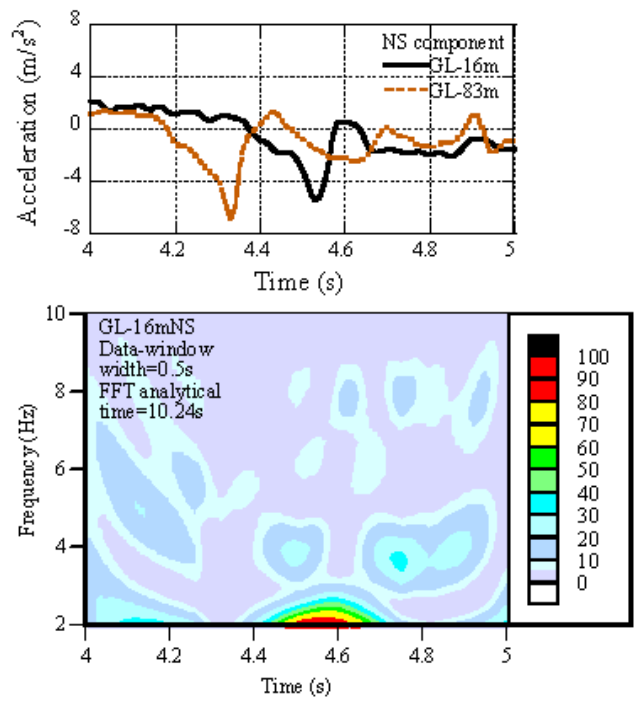

GL-16m NS

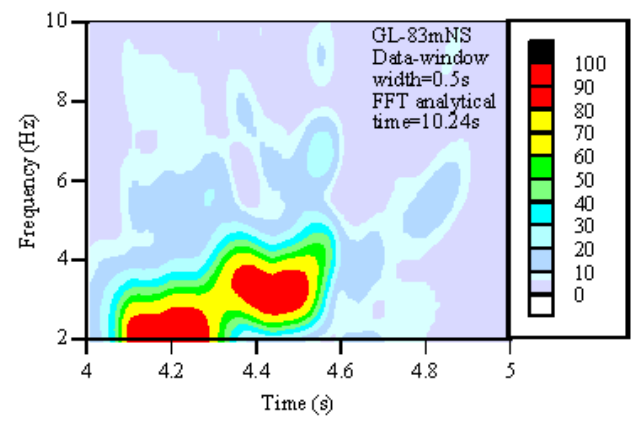

GL-83m NS
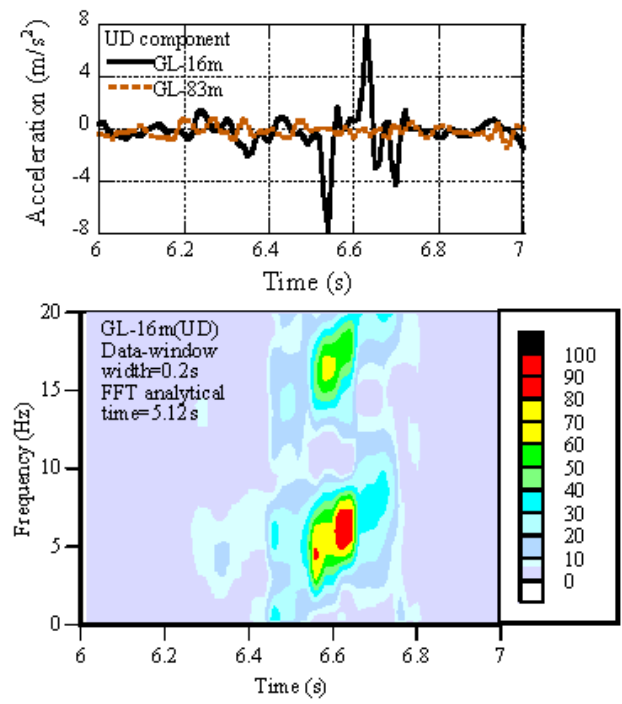

GL-16m UD

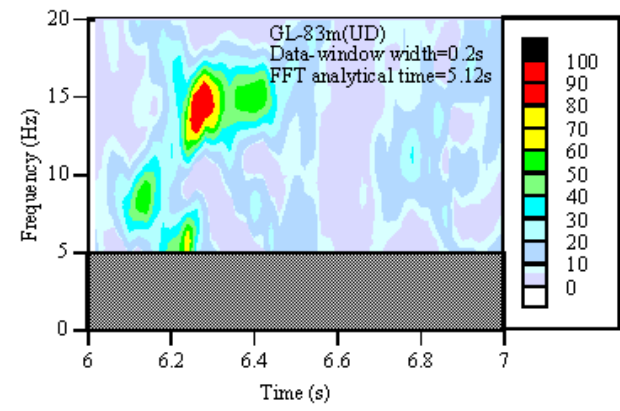

GL-83m UD

Fig.17 Non-stationary Fourier spectra of pulse wave

Table 3 Analysis conditions of non-stationary Fourier spectra

\begin{tabular}{|c|c|c|c|}
\hline component & Data-window width & Sampling frequency & Sweep interval time \\
\hline NS & $0.5 \mathrm{~s}$ & $0.098 \mathrm{~Hz}$ & $0.01 \mathrm{~s}$ \\
\hline UD & $0.2 \mathrm{~s}$ & $0.197 \mathrm{~Hz}$ & $0.01 \mathrm{~s}$ \\
\hline
\end{tabular}


The frequency property of the pulse wave of NS component can be analyzed as follows.

(1) The dominant components at GL-83m shift from $2.0 \mathrm{~Hz}$ to $3.1 \mathrm{~Hz}$.

(2) The dominant component at GL-16m is $2.0 \mathrm{~Hz}$, which is delayed $0.4 \mathrm{~s}$ from GL-83m.

The frequency property of UD component can be analyzed as follows.

(3) The dominant component at GL-83m is the frequency of $15 \mathrm{~Hz}$ at the time of $6.2 \mathrm{~s}$.

(4) The dominant component at GL-16m is the frequency of $6.1 \mathrm{~Hz}$ and $16.4 \mathrm{~Hz}$ at the time of $6.6 \mathrm{~s}$.

The maximum amplitude spectra of NS and UD components are illustrated in Fig.18.
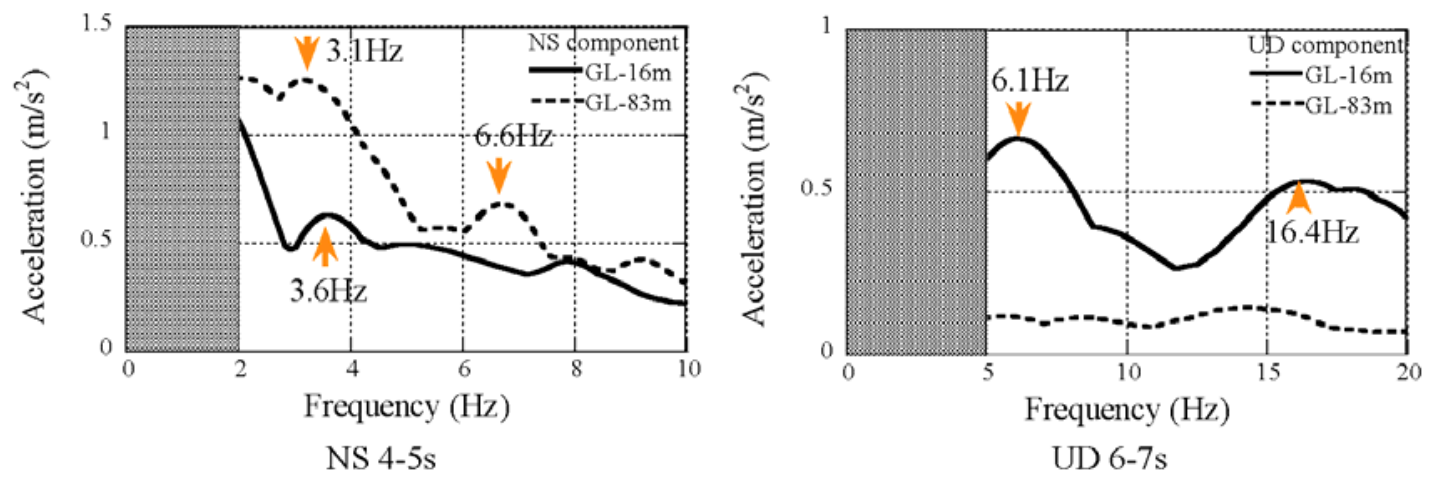

Fig.18 Maximum amplitude spectra of pulse waves

The property of the dominant components in NS component can be analyzed as follows.

(1) The gradually increasing process of the pulse wave is composed of the component of $2.0 \mathrm{~Hz}$ and the sharp decreasing process of the pulse wave related to the transient mode of $3.1 \mathrm{~Hz}$ at GL-16m and $3.6 \mathrm{~Hz}$ at GL-83m.

(2) The pulse wave at GL-83m is related to the frequency of $6.6 \mathrm{~Hz}$.

The property of dominant components in UD component can be analyzed as follows.

(3) The isolated pulse waves at GL-16m are composed of multi-components, which can be evaluated from the maximum amplitude spectra at the frequency of $6.1 \mathrm{~Hz}\left(0.66 \mathrm{~m} / \mathrm{s}^{2}\right)$ and $16.4 \mathrm{~Hz}\left(0.53 \mathrm{~m} / \mathrm{s}^{2}\right)$.

(4) The maximum amplitude spectra at GL-83m do not have any dominant component.

\subsection{Analysis of numerically integrated displacement profiles}

The numerically integrated displacement profiles and the maximum deformation of the underground are illustrated in Fig. 19. The maximum values of displacement are listed in Table 4. The amplitude of NS component is larger than that of EW component. 

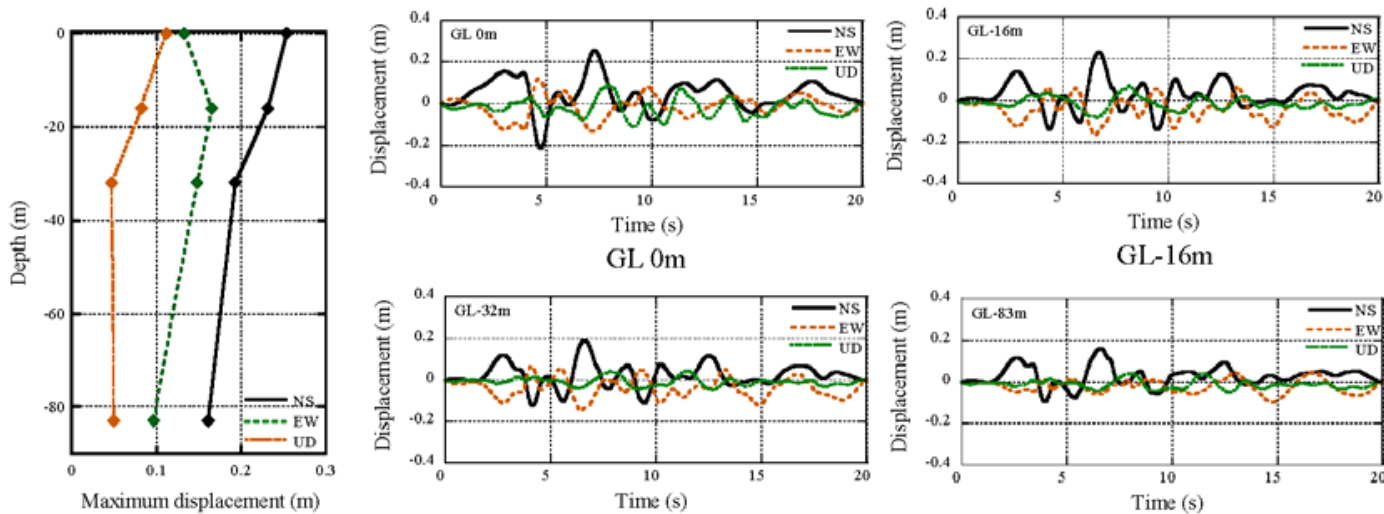

GL $0 \mathrm{~m}$

GL-16m

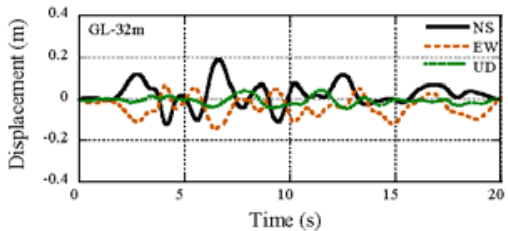

GL-32m

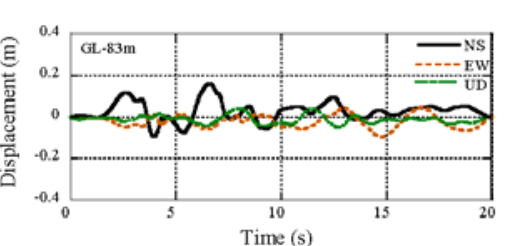

GL-83m

Fig.19 Maximum values and displacement profiles

Table 4 Maximum displacement (m)

\begin{tabular}{|c|c|c|c|}
\hline & NS & EW & UD \\
\hline GL 0m & 0.254 & 0.133 & 0.112 \\
\hline GL-16m & 0.232 & 0.165 & 0.082 \\
\hline GL-32m & 0.193 & 0.148 & 0.047 \\
\hline GL-83m & 0.161 & 0.097 & 0.05 \\
\hline
\end{tabular}

In the displacement profiles the principal shock from 2 to $8 \mathrm{~s}$ is enlarged in order to evaluate the amplification process (see Fig.20). The displacement profile at GL 0m differs from the other displacement profiles. The gradual increase of displacement from 0 to $0.15 \mathrm{~m}$ at GL $0 \mathrm{~m}$ occurs from 1.0 to $4.0 \mathrm{~s}$. The phase delay occurs as closer to surface from GL-83m.

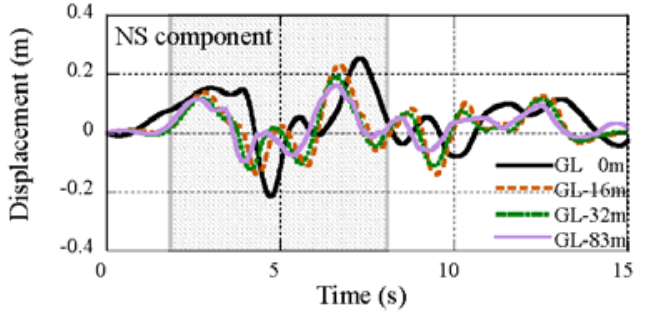

Global view

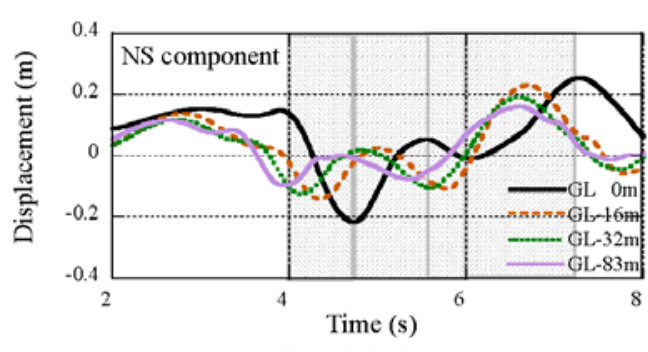

Partial view

Fig.20 Displacement of NS components

The deformation profile in the depth direction is illustrated with the time interval of $0.1 \mathrm{~s}$ (see Fig.21). The whipping mode appears from GL-32m to GL 0m, i.e. the direction of movement at GL $0 \mathrm{~m}$ is opposite to that at GL-83m and the peak-to-peak displacement at GL 0m amplified two times compared to that of GL-83m. On the other hand, the underground from GL-83m to GL-32m vibrates with the uniform deformation. 
The orbits in the horizontal plane at GL 0m and GL-83m are illustrated with the map of epicenter and measurement point in Fig.22. The movement in the orthogonal direction from the epicenter to the measurement point was dominant in the principal shock from 0 to 10 s.

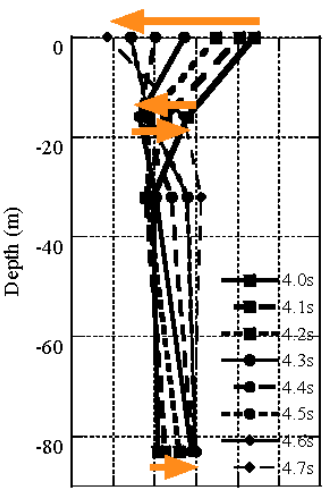

$\begin{array}{lllllll}-0.3 & -0.2 & -0.1 & 0 & 0.1 & 0.2 & 0.3\end{array}$

Displacement (m)

$4.0-4.7 \mathrm{~s}$

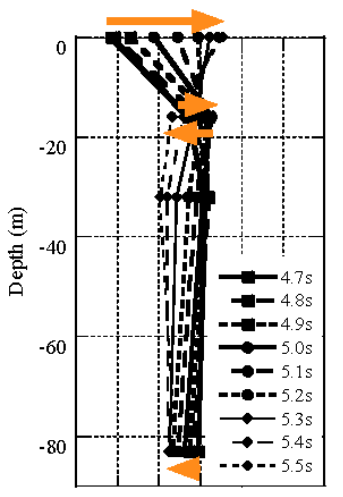

$\begin{array}{ccccccc}-0.3 & -0.2 & -0.1 & 0 & 0.1 & 0.2 & 0.3\end{array}$

Displacement (m)

$4.7-5.5 \mathrm{~s}$

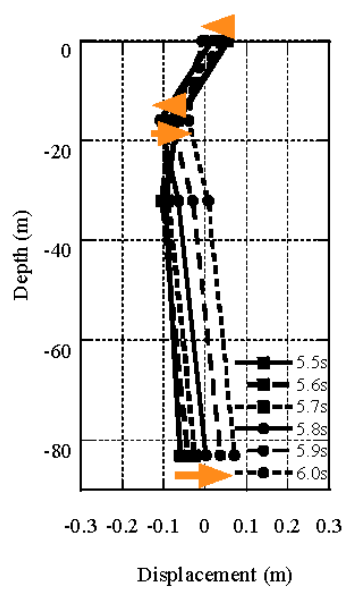

$5.5-6.0 \mathrm{~s}$

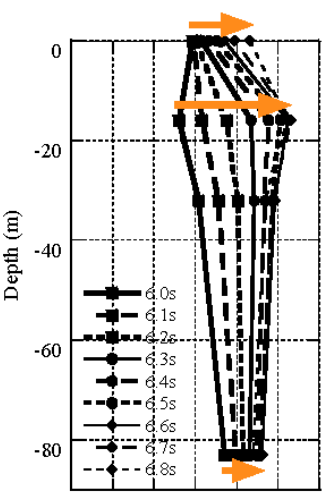

$\begin{array}{ccccccc}-0.3 & -0.2 & -0.1 & 0 & 0.1 & 0.2 & 0.3\end{array}$

Displacement (m)

$6.0-7.3 \mathrm{~s}$

Fig.21 Deformation profiles of NS components
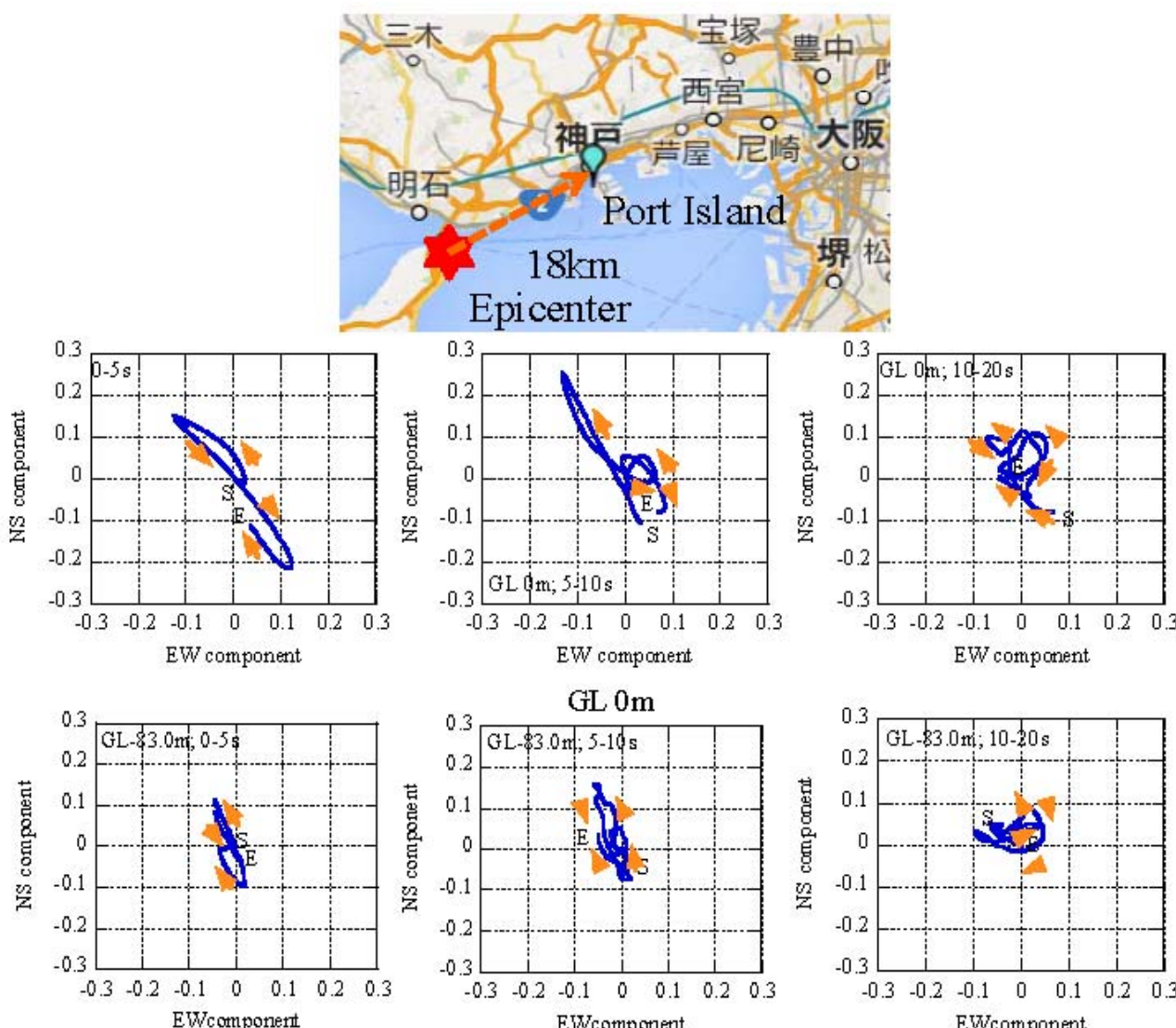

GL - 83m

Fig.22 Orbit of Port Island 


\subsection{Evaluation of deterioration ratio of soil stiffness}

The shear strain profiles are calculated as the fraction of the inter-story displacement profiles by the relative distance of neighboring observation points (see Fig.23). The part of the shear strain profiles from 4 to $9 \mathrm{~s}$ is enlarged in order to evaluate the amplitude and the phase in the depth direction. The amplitude is amplified and the phase is delayed as closer to the surface. The stationary vibration process can be observed as the peak-to-peak shear strain of 0.02 at the surface soil from GL $0 \mathrm{~m}$ to GL-16m.
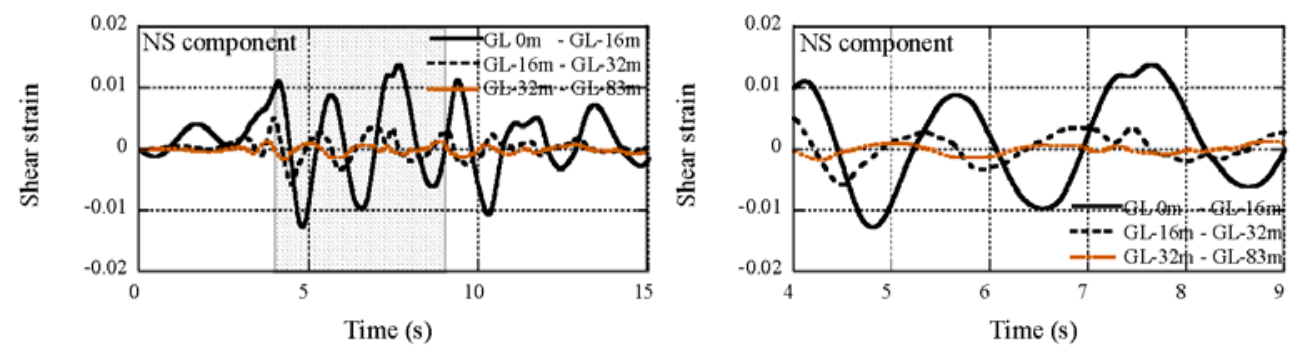

Fig.23 Shear strain profiles

The maximum values of shear strain are listed in Table 5. The maximum value of shear strain is 0.0138 in NS component between GL 0m and GL-16m.

Table 5 Maximum shear strain of inter-story

\begin{tabular}{|c|c|c|c|}
\hline Depth & NS & EW & UD \\
\hline GL 0m & 0.0138 & 0.0104 & 0.0070 \\
\hline GL-16m $\quad-32 m$ & 0.0058 & 0.0050 & 0.0035 \\
\hline GL-32m $\quad-83 m$ & 0.0017 & 0.0020 & 0.0002 \\
\hline
\end{tabular}

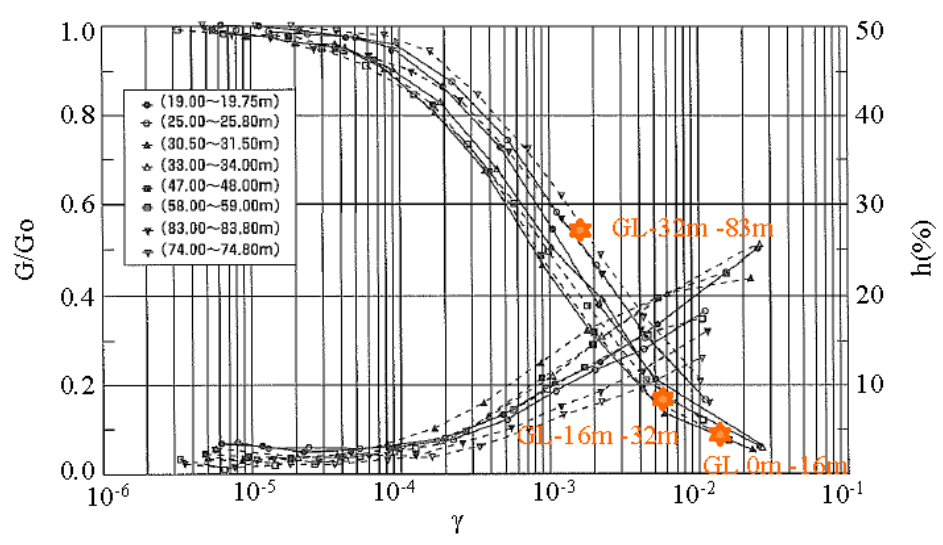

Fig.24 Characteristics of dynamic deformation of soil

The G- $\gamma$ relation has been investigated as the characteristics of dynamic deformation in the report of the PHRI [20]. The maximum values of NS component are plotted in Fig.24. The deterioration ratio of soil stiffness from GL $0 \mathrm{~m}$ to GL-16m is estimated to be $90 \%$ of initial stiffness. 
The evaluated value is coincident with the deterioration ratio evaluated by the frequency-shift of the dominant frequency.

\section{Seismic record including cyclic mobility phenomenon (K-NET; CHB024)}

In Chiba bay area, the reclamation by the sand pump method has been conducted to enlarge the housing area from 1960's. The depth of the artificial soil is 5 meters and the reclaimed soil is composed of sand and soil which are pumped up from the bottom of the sea at Tokyo bay.

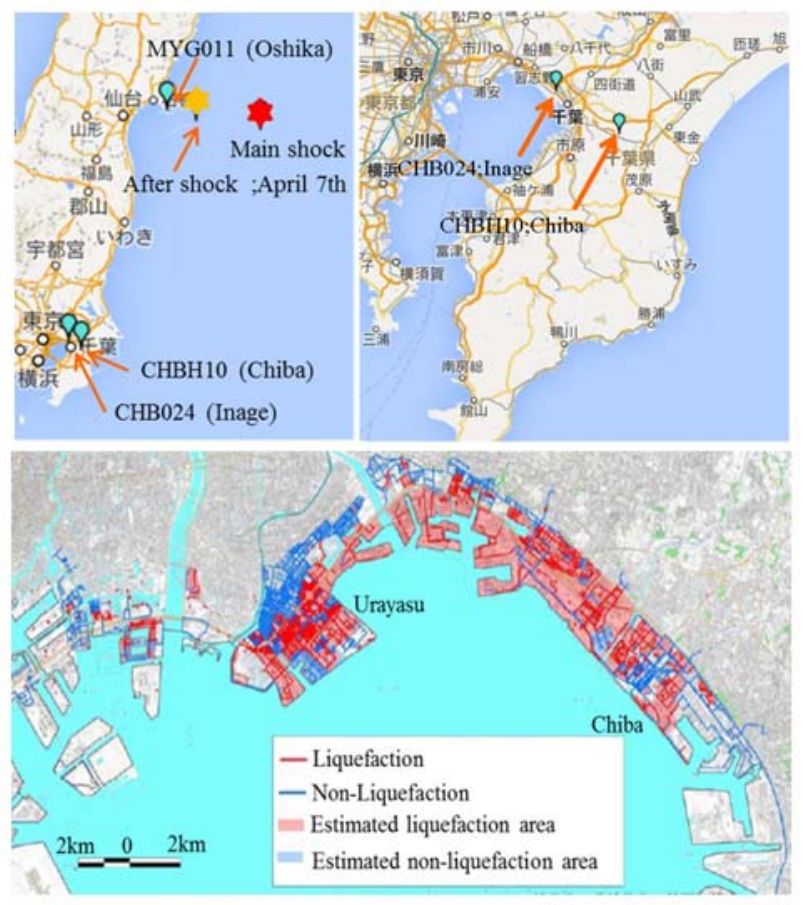

Fig.25 Site map and hazard at Chiba bay area [3]

The 2011 off the Pacific coast of Tohoku earthquake was the consolidated-type earthquake with Mw9.0 and the following tsunami after the earthquake caused severe hazard in the wide area of Japan. Many research reports have been published in the last three years after the earthquake event. In this section, the liquefaction hazard at Chiba bay area is discussed (see Fig.25). The liquefaction hazard which occurred far from the epicenter reminded us of the Mexico earthquake in 1985 (Mw8.0). The seismic record of SCT1 is analyzed in Appendix-2.

The Chiba Prefectural Environmental Research Center published the research report on the seismic hazard in 2012, in which the previous hazard by the Chiba Prefecture Eastward Offshore earthquake in 1987 was compared to evaluate the recurrence property of the liquefaction [2]. Many seismic records were measured in the wide area of Japan by the K-NET and the KiK-net [22]. The authors picked-up the seismic records of CHB024 (Inage), in which the singular pulse waves were observed in the later part of principal shock [13]. Then the seismic records of CHBH10 (Chiba) were 
used to evaluate the amplification property of CHB024. The borehole at CHBH10 was set at 1935m depth at the Boso plateau. The soil condition of CHBH10 is the typical soil layer at Kanto area named Pleistocene Shimosa group and Kazusa group (see Fig.26).

The MYG011 is positioned with the epicentral distance of 121km as shown in Fig.25 and the seismic records of the MYG011 were analyzed to investigate the property of seismic fault. The Chiba-bay area is $350 \mathrm{~km}$ far from epicenter of the 2011 off the Pacific coast of Tohoku earthquake as shown in Fig.25. The soil conditions of CHB024, MYG011 and CHBH10 were investigated by the National Research Institute for Earth Science and Disaster Prevention as shown in Fig.26.
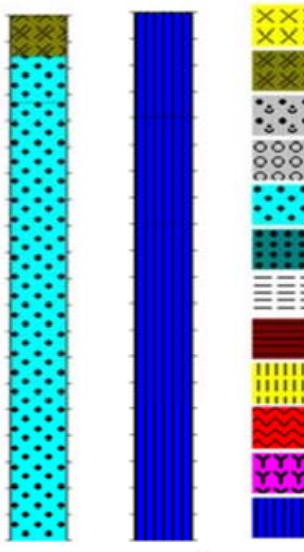

$x \times$
$x \times$ Surface soil

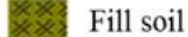

Gravel

oㅣ Gravelly soil

$\because \because$ Sand

Sandy soil

卞三三 Silt

IIIII Clay

IIIIIII Organic soil

Volcanic ash clay

Peat

Rock

CHB024 MYG011
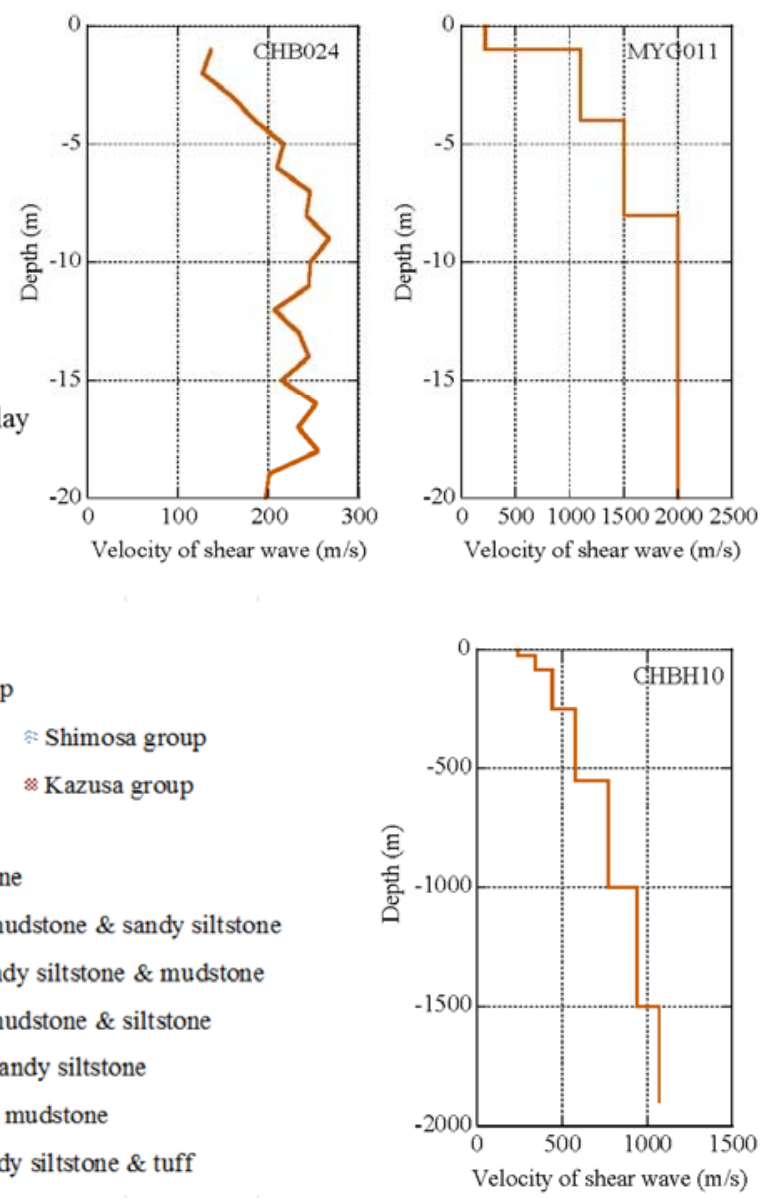

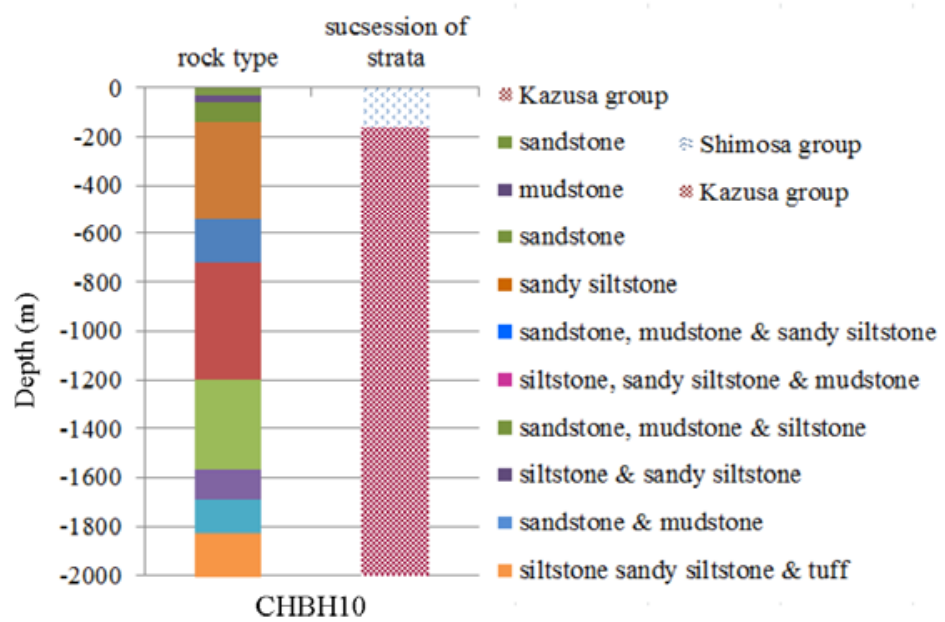

Fig.26 Soil condition and shear wave velocity

The underground of CHB024 consists of a sand layer from the surface to $20 \mathrm{~m}$ depth. The liquefaction hazard at Chiba bay area occurred at moth-eaten appearance as shown in Fig.25, which is related to several reasons. One was the reclaim method. The adopted hydraulic fill method changed the soil density in the horizontal distance from the vent of pumping-up pipe. The other was the difference of the countermeasure for the liquefaction [2]. 


\subsection{Amplification property of seismic records}

The aftershock of April $7^{\text {th }}$ (M7.1) occurred near the mainshock as shown in Fig.25. The measurement point of K-NET; MYG011 (Oshika) is situated near the epicenter with the distance of $38 \mathrm{~km}$ and the underground condition of MYG011 is the hard rock with the shear wave velocity larger than $1000 \mathrm{~m} / \mathrm{s}$. The maximum accelerations of the aftershock are larger than those of the mainshock as shown in Table 6. On the other hand the maximum accelerations of the mainshock are ten times larger than that of the aftershock at the seismic records of CHBH10 (borehole). In the seismic records of MYG011, the envelope shape of the principal shock at the aftershock is similar to the envelope shapes of both principal shocks at the mainshock.

The profiles of the seismic records at CHBH10-borehole are clearly different from those at MYG011 due to the following reasons.

(1) In the aftershock of the CHBH10, the difference of the arriving time of P-wave and S-wave is about 40 s, which is caused by the long distance from the epicenter.

(2) And the duration time of principal shock is 100 s, which is caused by the difference of the velocity in each frequency.

(3) In the mainshock of the MYG011, the duration times of both principal shocks are 30s.

(4) And it was detected that the interval time of both principal shocks was 50 second, which was shorter than the duration time of the principal shock at the CHBH10.

(5) In the mainshock of the CHBH10, a single principal shock was observed and the duration time was longer than 150s. This was caused by the superposition of both principal shocks.

(6) The maximum amplitude ratio (=the maximum amplitude of mainshock/ that of the aftershock) of the MYG011 is smaller than 1.0. On the other hand those of the CHBH10 are around 10.0. It can be understood that the propagation pass from the epicenter caused the distinct difference of the amplification property.

(7) The property of dominant components in the non-stationary Fourier spectra shows that the arriving time is delayed as the frequency becomes smaller. This propagation property caused the coupling of the first and the second shocks in the mainshock at the CHBH10.

The acceleration profiles of the mainshock and aftershock at the MYG011 and the CHBH10-Borehole are illustrated in Fig.27 as well as the non-stationary Fourier spectra of the aftershock. 

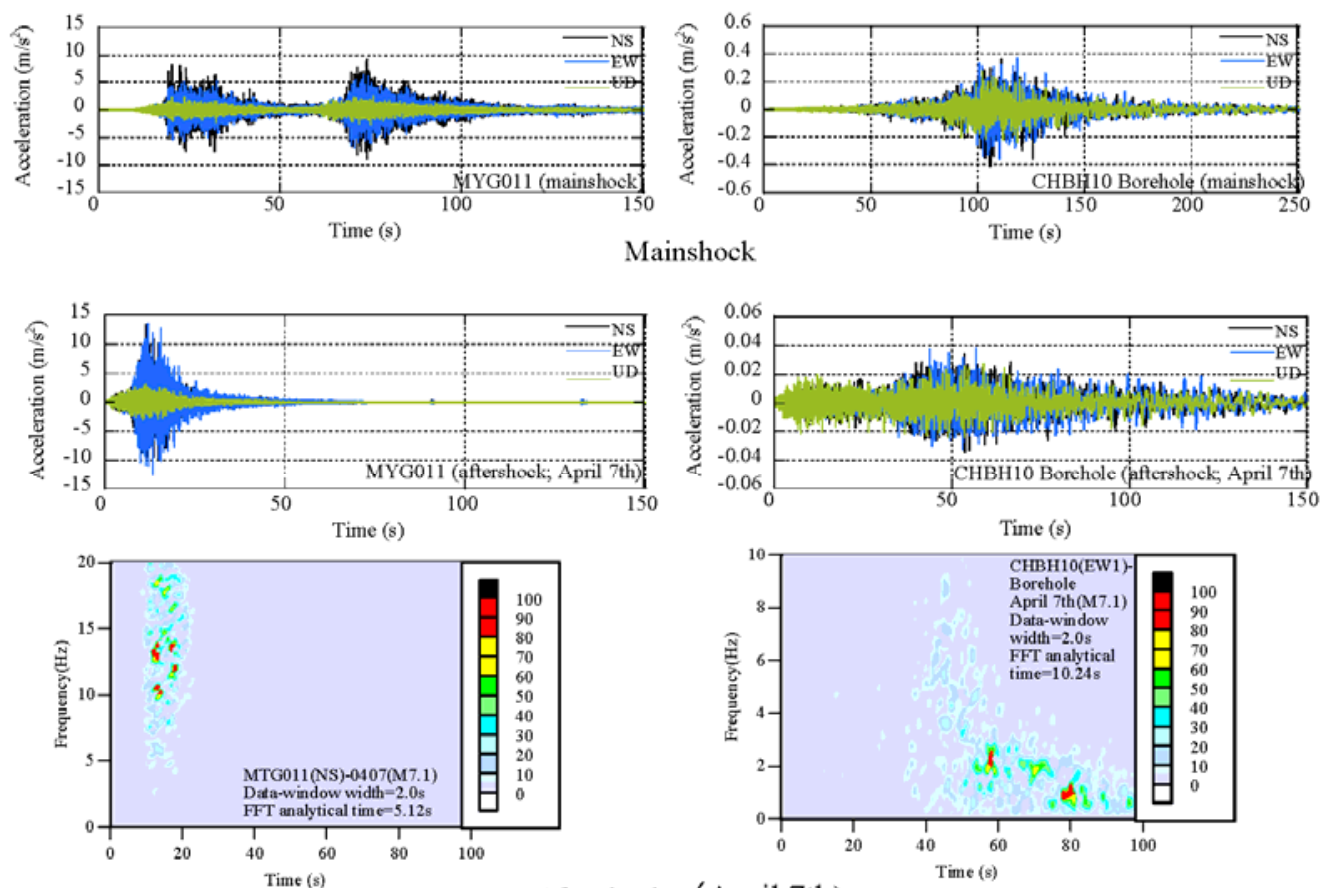

Aftershock (April 7th)

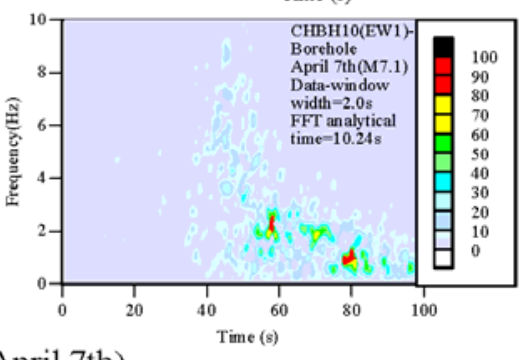

CHBH10 Borehole

Fig.27 Comparison of mainshock and aftershock (April $7^{\text {th }}$ )

Table 6 Maximum accelerations

\begin{tabular}{|c|c|r|r|r|r|r|r|r|r|}
\hline & \multicolumn{3}{|c|}{ Mainshock } & \multicolumn{3}{c|}{ Aftershock } & \multicolumn{3}{c|}{ Ratio of maximum value } \\
\cline { 2 - 10 } & \multicolumn{1}{|c|}{ NS } & EW & \multicolumn{1}{c|}{ UD } & \multicolumn{1}{c|}{ NS } & \multicolumn{1}{c|}{ EW } & UD & \multicolumn{1}{c|}{ NS } & \multicolumn{1}{c|}{ EW } & \multicolumn{1}{c|}{ UD } \\
\hline MYG011 & 9.210 & 6.882 & 2.539 & 13.288 & 13.562 & 3.016 & 0.693 & 0.507 & 0.842 \\
\hline CHB024 & 2.321 & 2.033 & 0.856 & 0.218 & 0.216 & 0.105 & 10.660 & 9.424 & 8.140 \\
\hline CHBH10-S & 1.065 & 1.314 & 0.884 & 0.163 & 0.208 & 0.101 & 6.521 & 6.317 & 8.737 \\
\hline CHBH10-B & 0.412 & 0.369 & 0.272 & 0.035 & 0.038 & 0.027 & 11.909 & 9.671 & 10.032 \\
\hline
\end{tabular}

The amplification property due to liquefaction at CHB024 is evaluated by the comparison of the seismic record at borehole of CHBH10, which was set at the underground of $1935 \mathrm{~m}$. The distance of measurement points between CHB024 and $\mathrm{CHBH} 10$ is $17.7 \mathrm{~km}$ which is shorter than $5 \%$ of epicentral distance of CHBH10 at the mainshock. The acceleration profile of CHB024 and those of CHBH10 at the surface and the borehole are illustrated in Fig.28. The characteristic pulse wave of CHB024 occurs at the later part of the principal shock from 120 to 130 s.
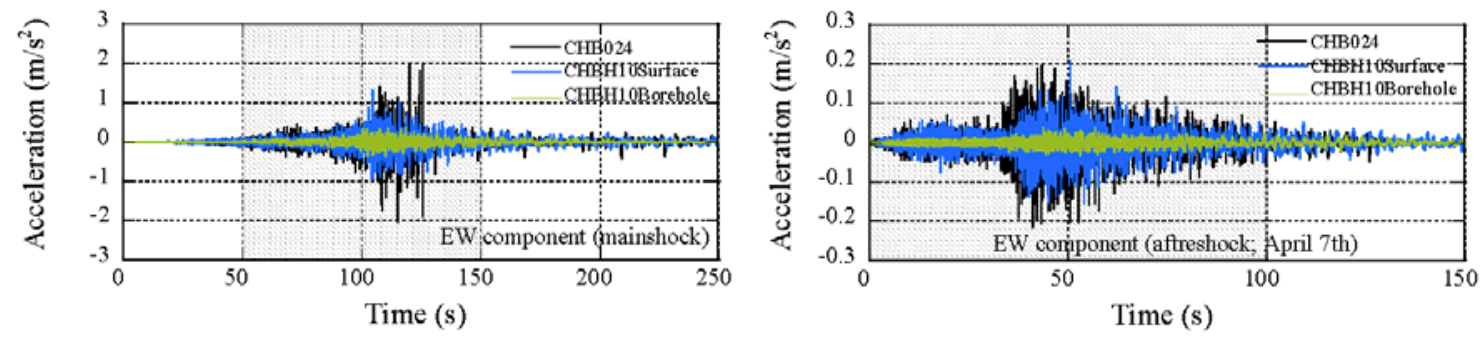

Fig.28 Comparison of acceleration profile of CHB024 and CHBH10 
Three seismic records of EW component are analyzed by the non-stationary Fourier spectra in Fig.29 and the maximum amplitude spectra are illustrated in Fig. 30. The analyzed time is from 50 to 150s of the mainshock and from 0 to 100s of the aftershock (shaded zone in Fig.28) and the frequency range of analysis is from 0 to $10 \mathrm{~Hz}$.
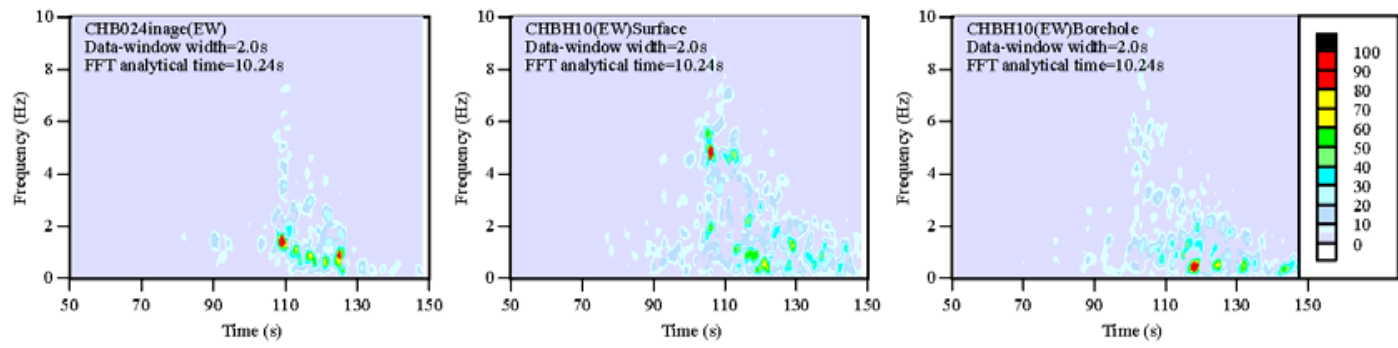

Mainshock
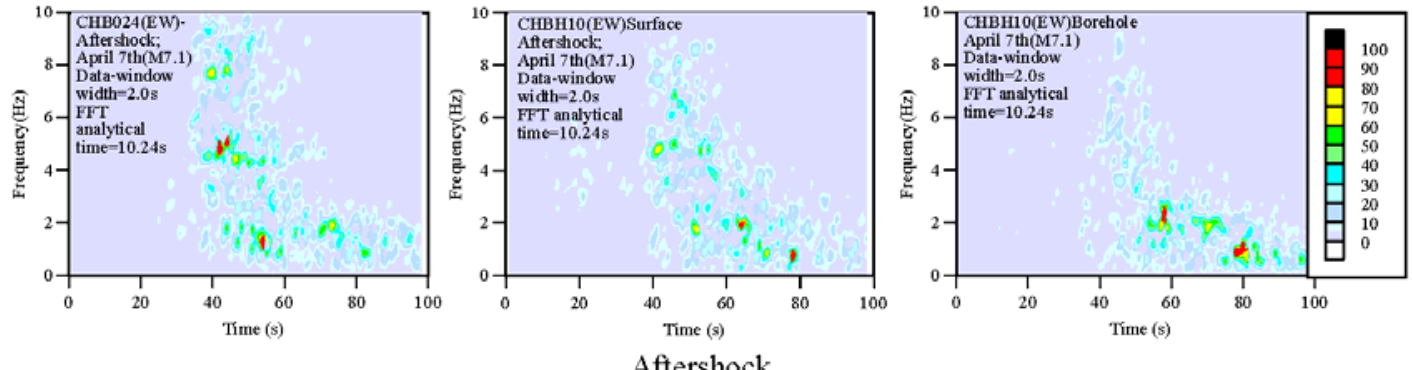

CHB024 (EW)

CHBH10 (EW) Surface

CHBH10 (EW) Borehole

Fig.29 Comparison of non-stationary Fourier spectra

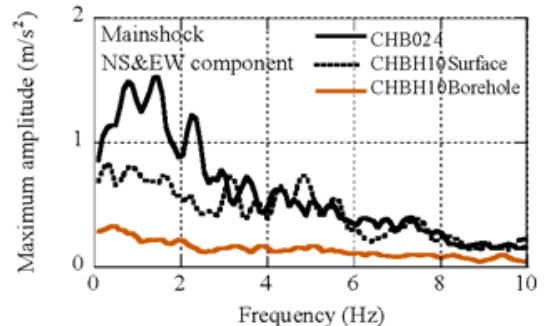

NS \& EW component (Mainshock)

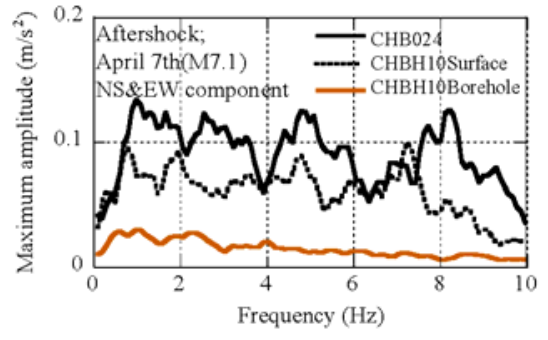

NS \& EW component (Aftershock)

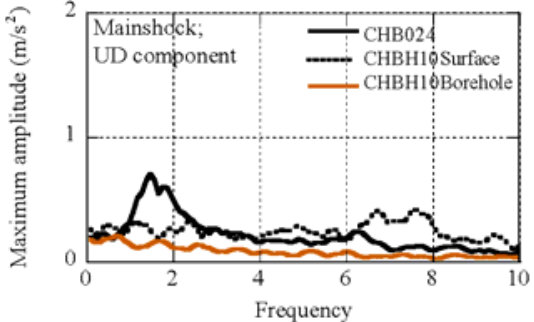

UD component (Mainshock)

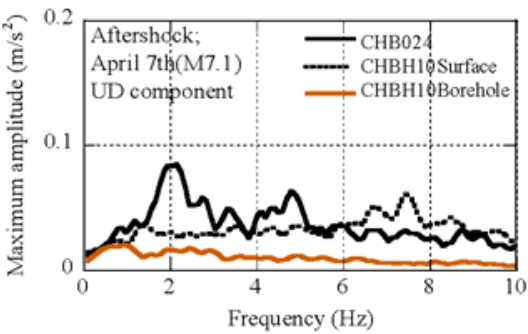

UD component (Aftershock)

Fig.30 Comparison of maximum amplitude spectra

The property of the dominant components can be analyzed as follows. 
(1) The scattering range of the aftershock is wider than that of the mainshock.

(2) The duration time of dominant components became longer toward to the lower frequency.

(3) The dominant components of the mainshock are concentrated to the low frequency range, such as the dominant components of the CHBH10 are amplified in the frequency range smaller than $5.0 \mathrm{~Hz}$ and those of the CHB024 are amplified in the frequency range smaller than $2.0 \mathrm{~Hz}$.

(4) The amplification factors of CHBH10 (surface) are the soil condition of the propagation path and the seismic event at the fault and that of CHB024 are related to the liquefaction as well as the amplification factors of CHBH10.

(5) The liquefaction is one of the major factors to amplify the seismic records.

The amplification property of CHB024 and CHBH10 (Surface) are evaluated as the fraction by the maximum amplitude of CHBH10 (Borehole) as shown in Fig.31.

$$
A_{R}\left(\omega_{i}\right)=F_{M A X}^{A c c}\left(\omega_{i}\right) /_{\text {Borehole }} F_{\text {MAX }}^{\text {Acc }}\left(\omega_{i}\right)
$$

The Hanning window is operated five times to make smooth the profile. The envelope spectra are adopted for the amplification ratio spectra of NS and EW components.
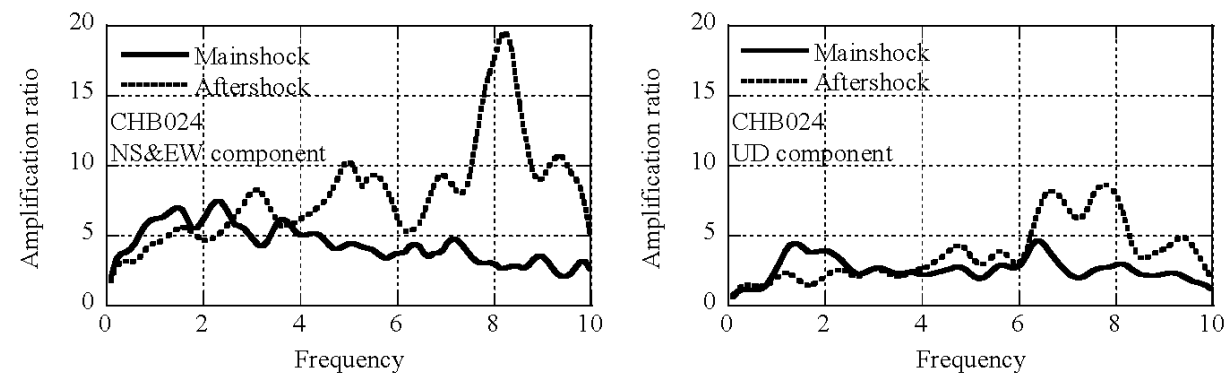

CHB024 (NS \& EW)

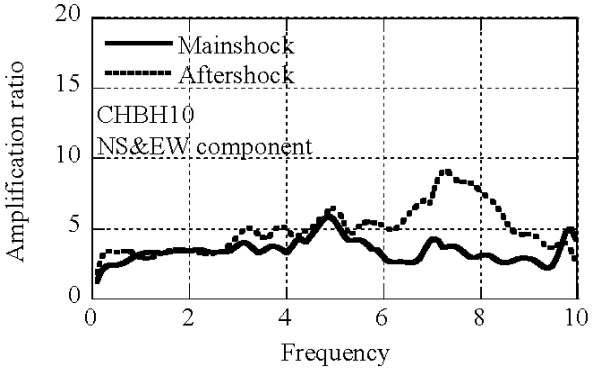

CHBH10 (NS \& EW)

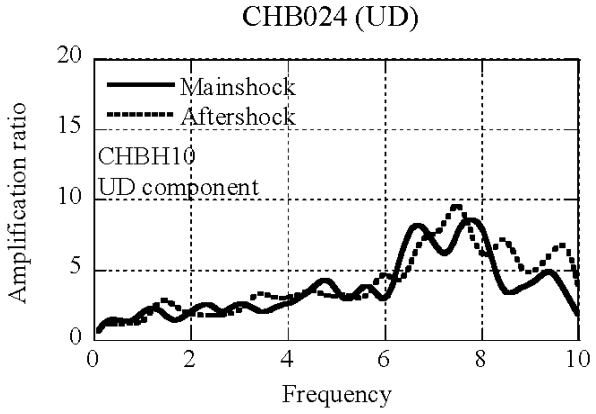

CHBH10 (UD)

Fig.31 Comparison of amplification ratio spectra

The property of the amplification ratio can be analyzed as follows.

(1) In the mainshock, the amplitude ratio of NS and EW components at the CHB024 is larger than 5.0 in the frequency range smaller than $3.0 \mathrm{~Hz}$.

(2) In the aftershock the amplitude ratio of NS and EW components at the CHB024 is larger than 5.0 in the frequency range larger than $4.0 \mathrm{~Hz}$. 
(3) The amplitude ratio at the CHBH10 resembles with the mainshock and aftershock in the frequency range smaller than $5.0 \mathrm{~Hz}$.

(4) In the aftershock at the CHBH10 the amplification ratio of NS and EW components is larger than 5.0 in the frequency range larger than $5.0 \mathrm{~Hz}$.

\subsection{Analysis of pulse wave by non-stationary Fourier spectra}

The seismic records of CHB024 from 50 to 150s are analyzed by the non-stationary Fourier spectra to evaluate the property of dominant components with the sampling frequency of $0.098 \mathrm{~Hz}$ (see Fig.32). The dominant components are scattered from 100 to 130s in which the pulse wave occurred after the principal shock.
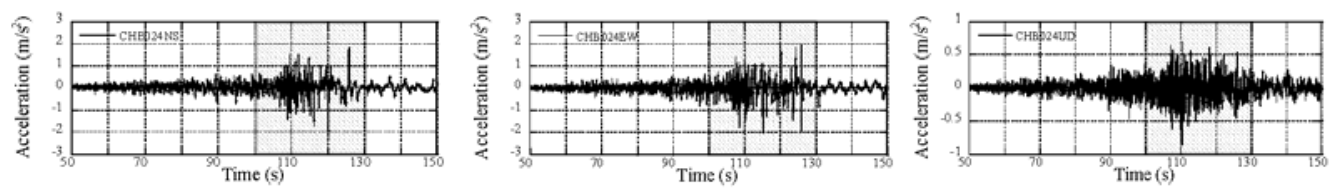

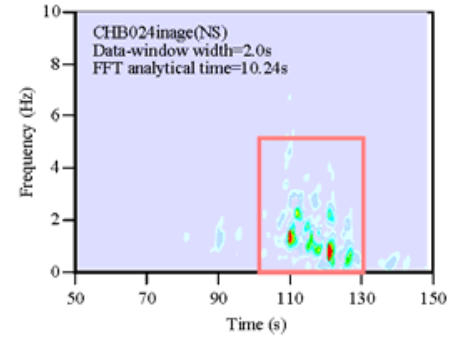

NS component

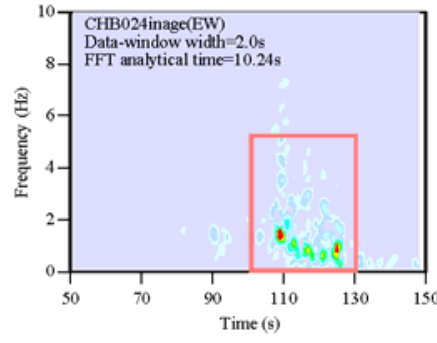

EW component

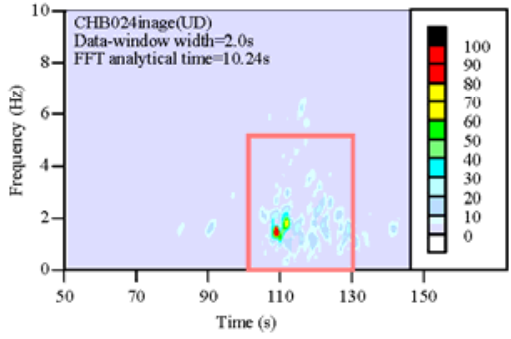

UD component

Fig.32 Global view of non-stationary Fourier spectra (CHB024)

In order to evaluate the occurring mechanism of the pulse wave, the non-stationary Fourier spectra with the sampling frequency of $0.049 \mathrm{~Hz}$ was analyzed for the duration time from 100 to $130 \mathrm{~s}$ as shown in Fig.33.
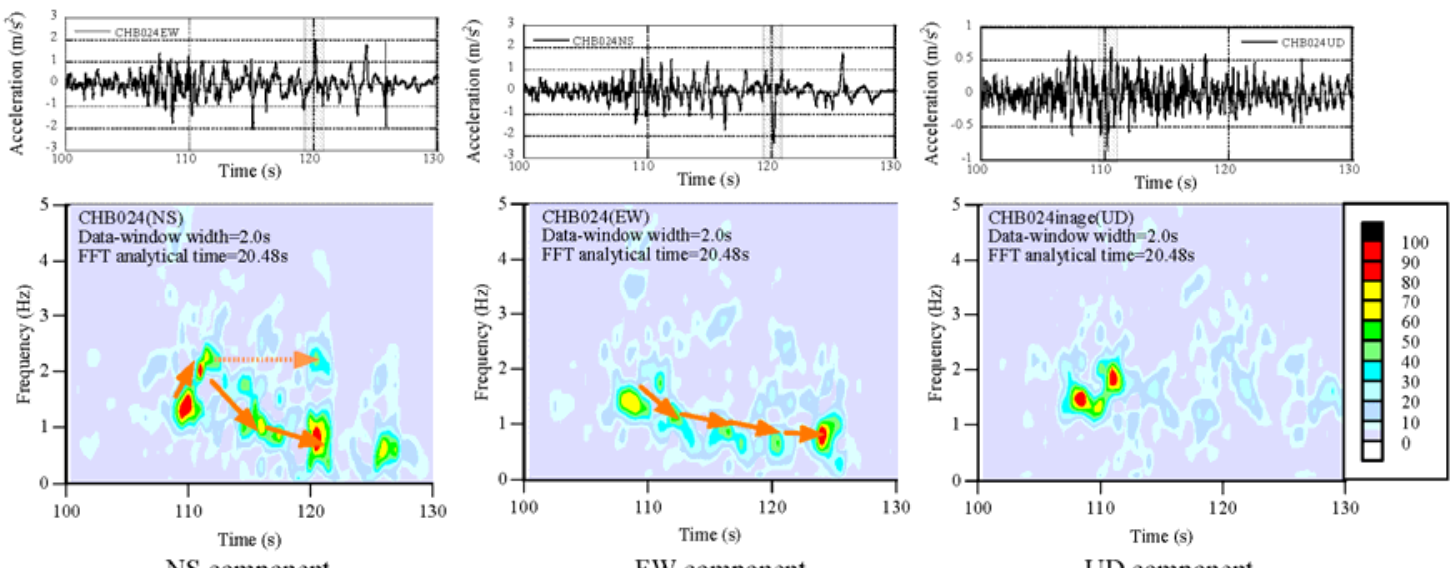

Fig.33 Partial view of non-stationary Fourier spectra (CHB024) 
(1) In the non-stationary Fourier spectra of NS component, the dominant frequency of $2.3 \mathrm{~Hz}$ at $110 \mathrm{~s}$ shifted to $0.8 \mathrm{~Hz}$ at $120 \mathrm{~s}$.

(2) The softening ratio was evaluated as $0.348(=0.8 \mathrm{~Hz} / 2.3 \mathrm{~Hz})$.

(3) The deterioration ratio of the stiffness was evaluated to be $88 \%$ by Eq. (2).

(4) In the acceleration profile of NS component, a pulse wave occurred at $120 \mathrm{~s}$. At that time a secondary dominant component of $2.3 \mathrm{~Hz}$ occurred with the primary component of $0.8 \mathrm{~Hz}$.

The pulse wave of the cyclic mobility was composed of the dual components. The cyclic mobility may result from the re-construction of lattice in the transient process of sand soil.

The maximum amplitude spectra corresponding to the global view and the partial view are illustrated in Fig.34. In the partial view of NS component, three dominant components are detected as $0.8 \mathrm{~Hz}\left(1.49 \mathrm{~m} / \mathrm{s}^{2}\right), 1.7 \mathrm{~Hz}\left(1.16 \mathrm{~m} / \mathrm{s}^{2}\right)$ and $2.3 \mathrm{~Hz}\left(1.17 \mathrm{~m} / \mathrm{s}^{2}\right)$.

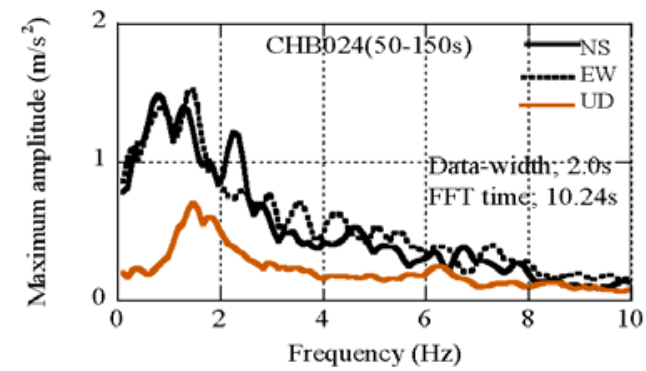

Global view

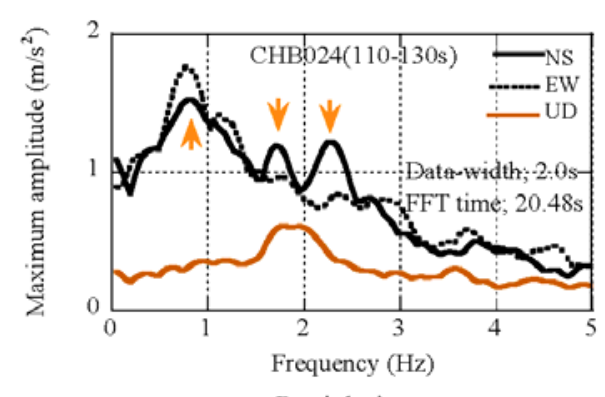

Partial view

Fig.34 maximum amplitude spectra of CHB024 (Inage)

\subsection{Analysis of ground movement by numerically integrated displacement profiles}

The numerically integrated displacement profiles from 80 to 140s and the dominant part from 115 to 130s are illustrated in Fig.35.
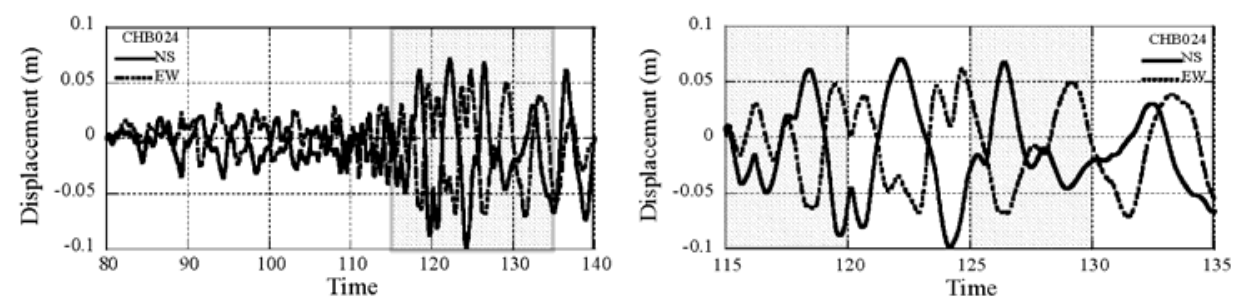

Fig.35 Displacement profiles of CHB024

Using the displacement profiles of NS and EW components, the orbit in the horizontal plane is illustrated for four parts with the duration time of 5 s as shown in Fig.36. The orientation of the orbit is coincident with the site map. The principal axis of orbit in the first two cycles is the direction from the epicenter to the measurement site and the orthogonal direction movement is observed. Furthermore the circular movement is observed during 130 to 135 s, which is considered as Love wave. 


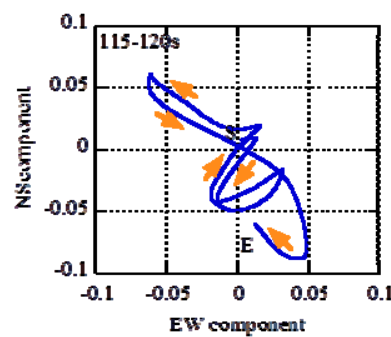

115-120s

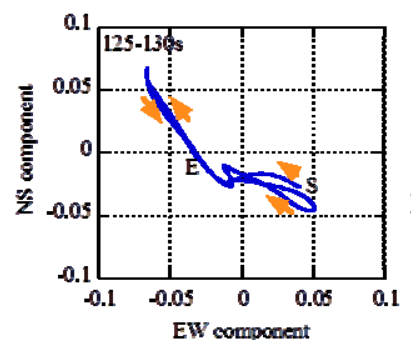

$125-130$ s

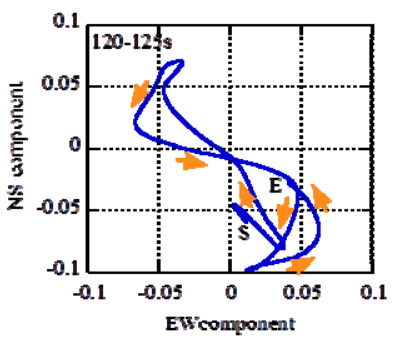

$120-125 \mathrm{~s}$

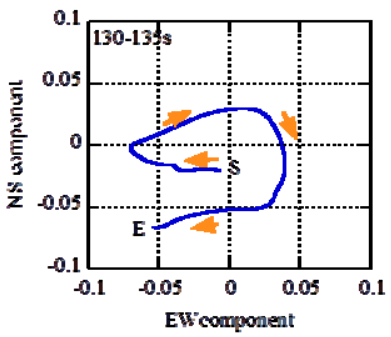

$130-135 \mathrm{~s}$

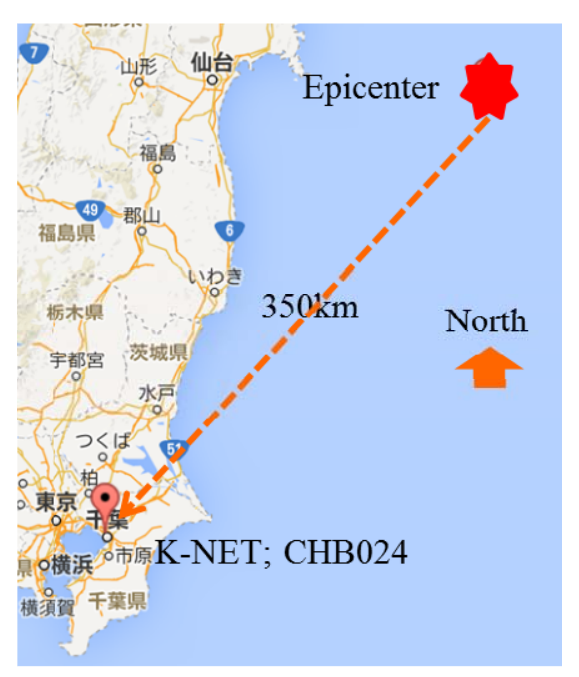

(http:/hucc.hokudai.ac.jp/ $\sim$ x10508/gomaplv7.html)

Fig.36 Orbit of CHB024 in horizontal plane

The displacement profiles of NS and EW components from 115 to 135s have a shape of dual peaks, which were analyzed by the non-stationary Fourier spectra with the window-width of $4.0 \mathrm{~s}$ (see Fig.37). The dual peaks of the wave are composed of dual components. The frequency of primary components alternatively shifted from $0.3 \mathrm{~Hz}$ to $0.2 \mathrm{~Hz}$ with the amplitude of $0.3 \mathrm{~m}$ and the frequency of secondary mode is $0.6 \mathrm{~Hz}$ with the amplitude of $0.13 \mathrm{~m}$.
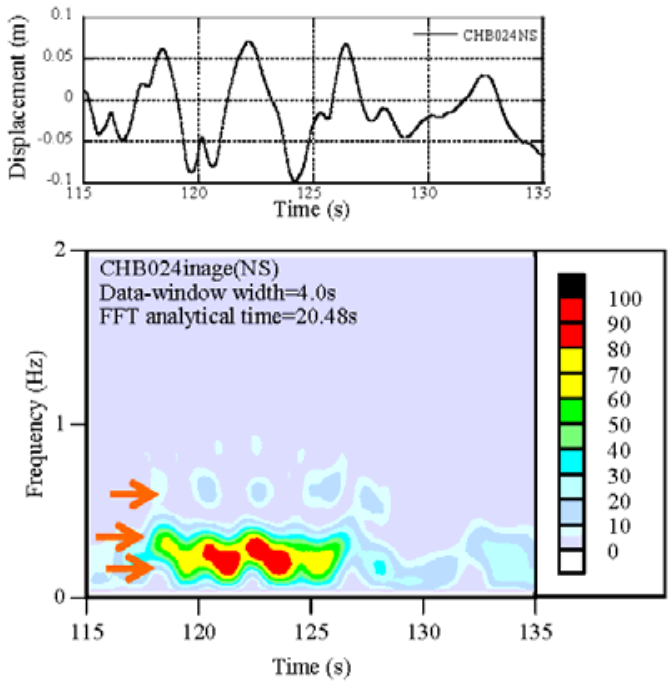

NS component
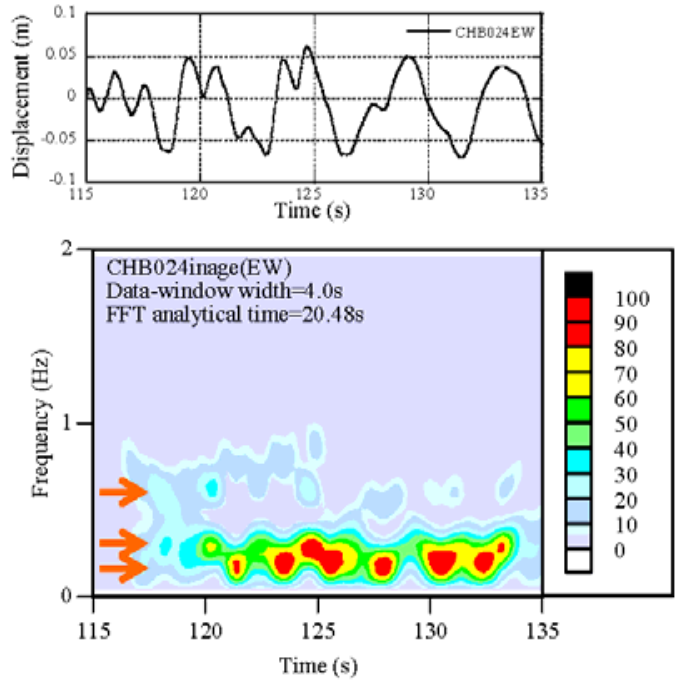

EW component

Fig.37 Non-stationary Fourier spectra of displacement profile (CHB024)

The amplitude was evaluated by the maximum amplitude spectra (see Fig.38). In NS component, the amplitude of the primary mode is larger than $0.3 \mathrm{~m}$ and that of the secondary mode is $0.13 \mathrm{~m}$. 


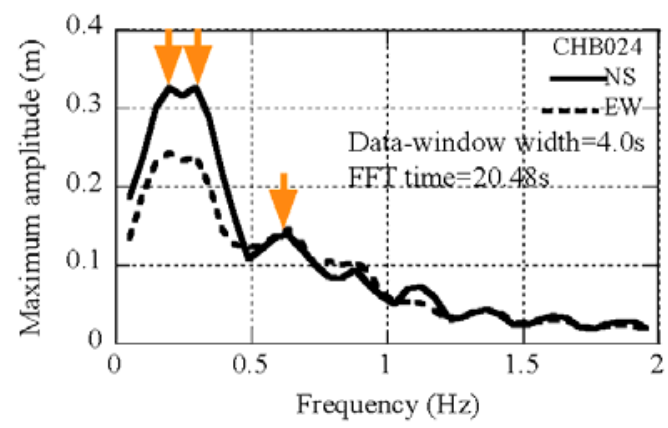

Fig.38 Maximum amplitude of displacement profile (CHB024)

\section{Conclusions}

Focusing on the amplification of acceleration profile by the pulse wave, two analytical methods were adopted for analysis of properties of soil liquefaction. One is the non-stationary Fourier spectra to evaluate the distribution property of dominant components in the transient process. The other is the numerically integrated displacement profile to evaluate the plastic state in the seismic behavior.

The following findings were obtained from the analytical results of the seismic records.

(1) From the seismic records at Kawagishi-cho of Niigata-ken earthquake in 1964, the shift of dominant frequency from high frequency to low frequency was evaluated by the non-stationary Fourier spectra and the deterioration ratio of soil stiffness was estimated to be $90 \%$.

(2) From the seismic records at Port Island of southern Hyogo prefecture earthquake in 1995, the shear-strain profiles of underground were calculated from the relative displacement of underground. Using the G- $\gamma$ relation, the deterioration ratio of soil stiffness was evaluated to be $90 \%$, which is coincident with the value estimated by the frequency-shift.

(3) From the non-stationary Fourier spectra of the mainshock and the aftershock of the 2011 off the Pacific coast of Tohoku earthquake, the property of the dominant components in the frequency and time domains was detected. The difference of the acceleration profiles between the MYG011 and the CHBH10 may be caused by the propagation property of the dominant components.

(4) In the seismic records of CHB024, the pulse wave in the later of the principal shock, called the cyclic mobility phenomenon, was detected that the pulse wave was caused by the secondary mode. The amplification property was evaluated using the seismic record at CHBH10 (Borehole).

\section{Acknowledgement}

The authors are grateful to National Research Institute for Earth Science and Disaster prevention, Port and Airport Research Institute for providing the seismic data. 


\section{References}

[1] Arai, H. (2012) "Number of Equivalent Cyclic Shear for Liquefaction at Tokyo Bay Area during the 2011 off the Pacific Coast of Tohoku Earthquake”, No.784, 47 ${ }^{\text {th }}$ Annual meeting of the Japanese Geotechnical Society

[2] Chiba Prefectural Environmental Research Center (2012), "Research Report G-8 LiquefactionFluidization Phenomena on Boso Peninsula at the 2011 Earthquake off the Pacific Coast of Tohoku, Central Japan: Part1-5”

[3] National Institute for Land and Infrastructure Management, Ministry of Land, Infrastructure, Transport and Tourism, Japan \& Building Research Institute, Incorporated Administrative Institute, Japan (2012), "Report on Field Surveys and Subsequent Investigations of Building Damage Following the 2011 off the Pacific coast of Tohoku Earthquake”, Technical note (ISSN 1346-7328), Building Research Data (ISSN0286-4630), March 2012

[4] Ministry of Land, Infrastructure, Transport and Tourism, Kanto Regional Bureau (2011) "Report: Survey on the liquefaction phenomenon at Kanto district during the 2011 off the Pacific coast of Tohoku earthquake”

[5] Kamagata, S. (1991). "Non-stationary spectra for seismic response control”, News \& Topics Research \& Development Structural Engineering (KRCEE0019111501), Kobori Research Complex (in Japanese).

[6] Japan Nuclear Energy Safety Organization (2009). "Analysis of seismic records to evaluate the interaction between the building and the surrounding soil”, March 2009 JNES/SSD09-004 (in Japanese) (http://www.jnes.go.jp/content/000016346.pdf)

[7] Kamagata, S. and Takewaki, I. (2013) “Occurrence mechanism of recent large earthquake ground motions at nuclear power plant sites in Japan under soil-structure interaction”, Earthquakes and Structures, Vol.4, No.5, 557-585.

[8] Kojima, K., Kamagata, S. and Takewaki, I. (2014) "A new interpretation of large amplitude earthquake acceleration from non-linear local soil-structure interaction”, Elsevier, Nuclear Engineering and Design 273 (2014), 271-287

[9] Kamagata, S. and Takewaki, I. (2013) "New insights into seismic behavior of building and surrounding soil at Hamaoka nuclear power station during Suruga Bay earthquake in 200)”, Elsevier, Soil Dynamics and Earthquake Engineering 53, 73-91.

[10]Kamagata, S. and Takewaki, I. (2013) "Role of records during the 2011 off the Pacific coast of Tohoku earthquake in seismic resistant design of nuclear power station” Int. J. of Earthquake Engineering and Hazard Mitigation (IREHM), 1(1), 9-21

[11]Niigata Local Meteorological Office, "Seismic (Tsunami) Hazard of Niigata Prefecture", (http://www.jma-net.go.jp/niigata/menu/bousai/seis_disaster.shtml) (in Japanese)

[12]Japan Association for Earthquake Engineering Bulletin of JAEE, "Special Issue on Property and 
Hazard of Seismic Ground Motion”, No.9 January 2009

[13]Kamagata, S. \& Takewaki, I. (2014) “Analysis of liquefaction behavior during the 2011 off the Pacific coast of Tohoku earthquake", Proceedings of the $14^{\text {th }}$ International Conference of the International Association for Computer Methods and Advances in Geomechanics, September 22-25, 2014, Kyoto, Japan

[14]Castro, G. (1975) "Liquefaction and cyclic mobility of saturated sand”, Journal of Geotechnical Eng. Div, ASCE 101 (GT6), 551-569

[15]Castro, G., and Poulos, S. J. (1977) "Factors affecting liquefaction and cyclic mobility”, $J$. Geotechnical Eng. Div., ASCE 103(GT6), 501-506

[16]Seed H. B. (1979), "Soil liquefaction and cyclic mobility evaluation for level ground during earthquake”, J. Geotechnical Eng. Div., ASCE105 (GT2), 201-255

[17]Idriss I. M. and Boulanger R. W. (2008) “Soil Liquefaction during Earthquakes” Earthquake Engineering Research Institute, MNO-12

[18]Elgamal A., Yang Z., Parra E. and Ragheb A. (2009) "Modeling of cyclic mobility in saturated cohesionless soils”, International Journal of Plasticity 19, 883-905

[19]Tokimatsu K. and Yoshimi Y., "Criteria of soil liquefaction with STP and fines content”, accepted at http://www.iitk.ac.in/nicee/wcee/article/8_vol3_255.pdf

[20]The Port and Harbour Research Institute Ministry of Transport, Japan, "Damage to Port and Port-related Facilities by the 1995 Hyogoken-nanbu Earthquake”, Technical Note of the Port and Harbour Research Institute, No.857, Mar 1997

[21]Nasu, M and Mimura, Y (2005), "A consideration of effect of ground upon propagating behavior of seismic motion in the Port island during the 1995 Hyogoken-nanbu earthquake”, Transactions of Japan Society of Civil Engineering, accepted at http://library.jsce.or.jp/jsce/open/ 00578/2005/28-0029.pdf (in Japanese)

[22]National Research Institute for Earth Science and Disaster Prevention, "Strong-motion Seismograph Networks (K-NET, KiK-net)”

[23]Okada, T. “Report on 1985 Mexico Earthquake” UDC SEISAN KENKYU 38(4), April 1986 


\section{Appendix-1 Influence of data-window width}

The parameters of non-stationary Fourier spectra are decided from analytical results of sinusoidal waves.

(1) Data-window width

Some sinusoidal waves with the frequency of $1.0 \mathrm{~Hz}$ are analyzed with three kinds of Data-window width, such as $1.0 \mathrm{~s}, 1.5 \mathrm{~s}$ and $2.0 \mathrm{~s}$. The longer data-window width than the dominant component mislead the occurrence time of dominant component (see Fig.C1).The longer data-window width than the dominant component has no influence on the maximum amplitude spectra (see Fig.C2).

In the analysis of seismic records the dominant frequency can be estimated from the shape of seismic record, namely pulse wave, cyclic wave. The suitable data-window is decided from some case study of data-window width.

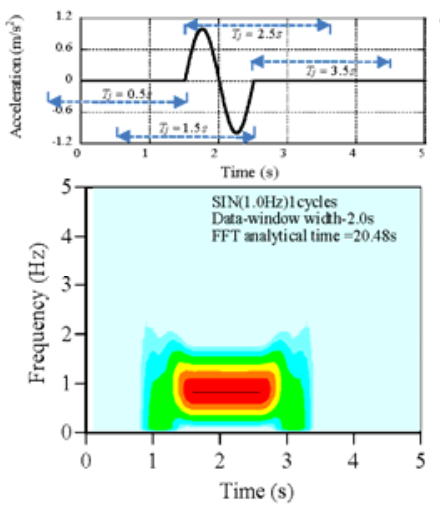

Data-window width $2.0 \mathrm{~s}$

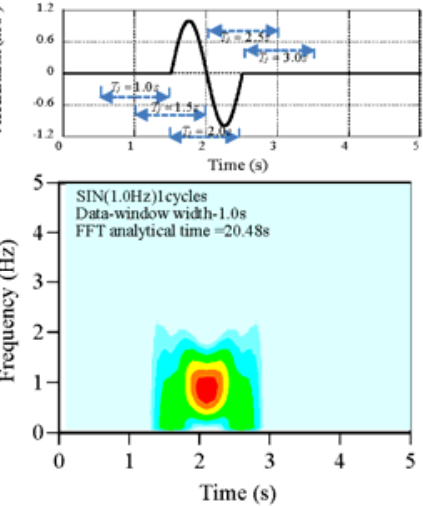

Data-window width $1.0 \mathrm{~s}$

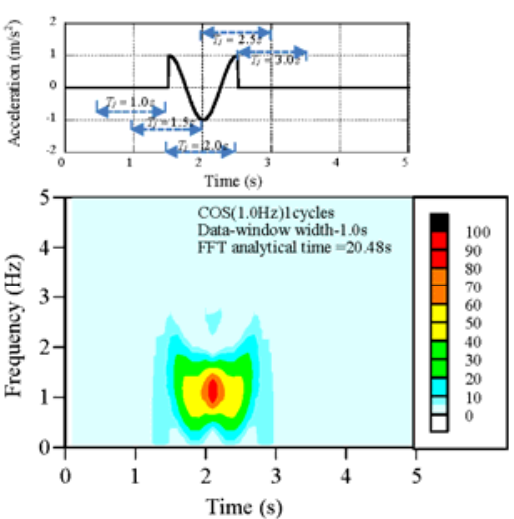

Data-window width $1.0 \mathrm{~s}$

Fig.A1-1 Comparison of non-stationary Fourier spectra
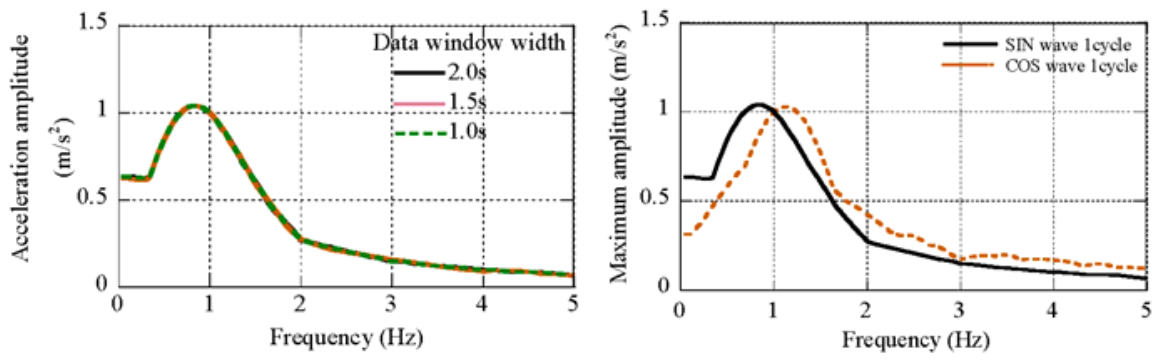

Fig.A1-2 Comparison of maximum amplitude spectra

The three cycle of sinusoidal wave is analyzed by the data-window width of $2.0 \mathrm{~s}, 1.5 \mathrm{~s}$ and $1.0 \mathrm{~s}$. The longer data-window width than dominant component misleads the occurrence time of dominant component. The frequency of dominant component changes cyclically from $0.83 \mathrm{~Hz}$ to $1.1 \mathrm{~Hz}$, which is caused by the difference of phase at each sweeping time. 


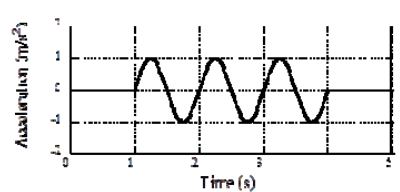

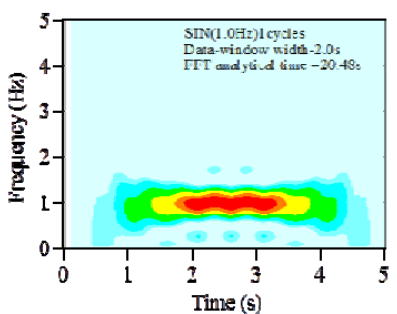

Data-window widfh $=2.0 \mathrm{~s}$

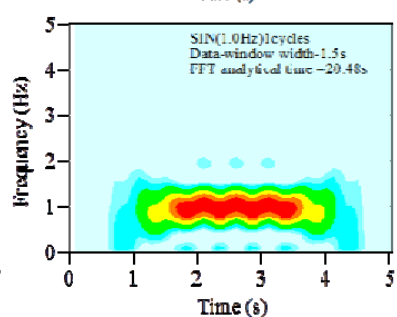

Data-window width-1.5s

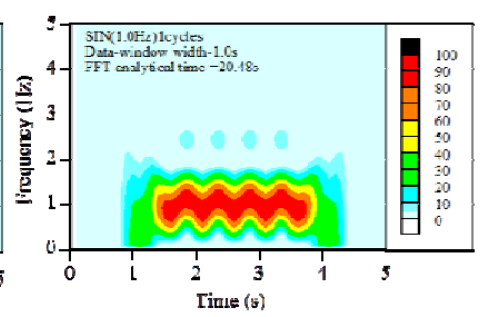

Data-window width-1.0s

Fig.A1-3 Comparison of data-window width in non-stationary Fourier spectra

The maximum amplitude spectra suggest an important condition of data-window width (see Fig.A1-4). The longer data-window width than the duration of dominant component misleads the maximum amplitude of dominant component. The shorter data-window width than the duration of dominant component misleads the frequency of dominant component.

(2) Sampling frequency

The distribution property and the maximum amplitude spectra (see Fig.A1-4) of dominant component has less difference in three cases of sampling frequency, such as $0.0488 \mathrm{~Hz}, 0.0977 \mathrm{~Hz}$ and $0.195 \mathrm{~Hz}$. The adopted sampling frequency is sufficiently smaller than the frequency of SIN wave $(1 \mathrm{~Hz})$.

(3) Sweep interval time

The non-stationary Fourier spectra of SIN wave (1cycle) are compared with three kinds of sweep interval time, such as $0.05 \mathrm{~s}, 0.1 \mathrm{~s}$ and $0.2 \mathrm{~s}$. Three sweep interval times are smaller than the period of dominant component (1.0s), therefore less difference is observed in the analytical results (see Fig.A1-4).

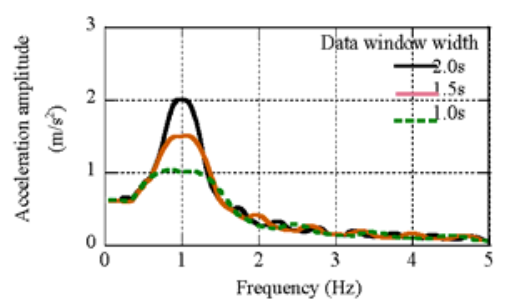

Data-window width

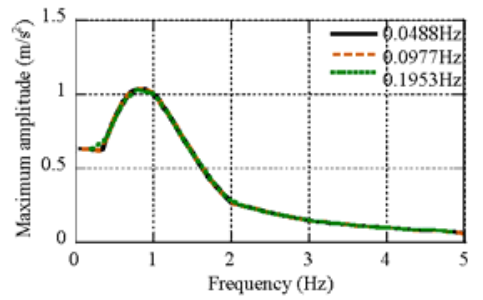

Sampling frequency

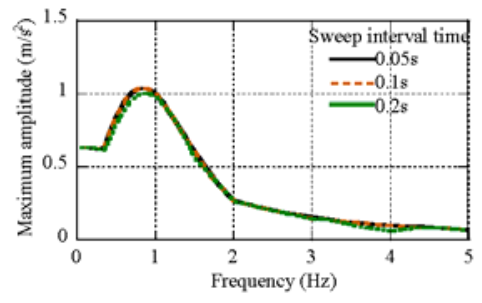

Sweep interval time

Fig.A1-4 Comparison of maximum amplitude spectra 


\section{Appendix-2 Seismic record of Mexico earthquake}

The hazard due to liquefaction at the Chiba-bay area reminded us of the Mexico earthquake in 1985 (Mw 8.0). That earthquake caused the hazard due to liquefaction at Mexico City which was $350 \mathrm{~km}$ far from the epicenter [23] (see Fig.A2-1). The fault offset was 3.0m and was smaller than that of the 2011 off the Pacific coast of Tohoku earthquake which was 5.3m. Mexico City is located at the reclaimed land of the lake Texcoco. The earthquake was amplified by the reflected wave by the hard base of the lake.

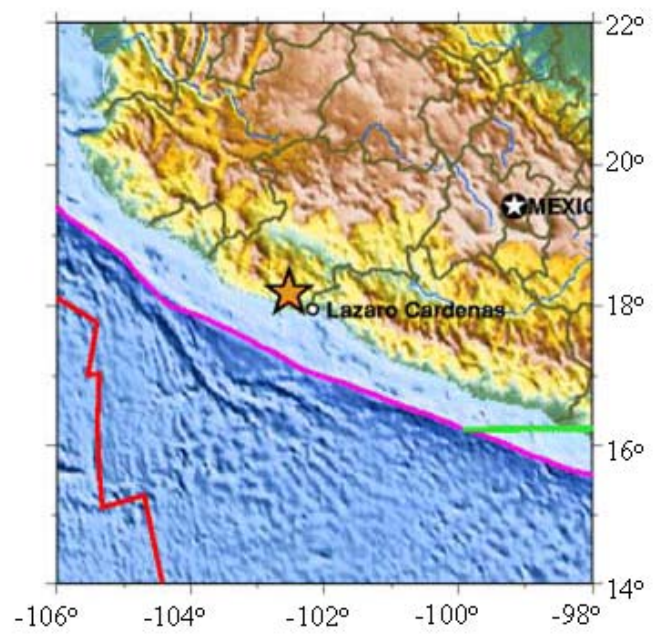

Fig.A2-1 1985 Mexico earthquake

(http://earthquake.usgs.gov/earthquakes/world/events/1985_09_19.php)

The profile of the mainshock from 50 to 70 s was analyzed in the frequency range below $2.0 \mathrm{~Hz}$ with the sweeping interval time of 0.2s as shown in Fig.A2-2.
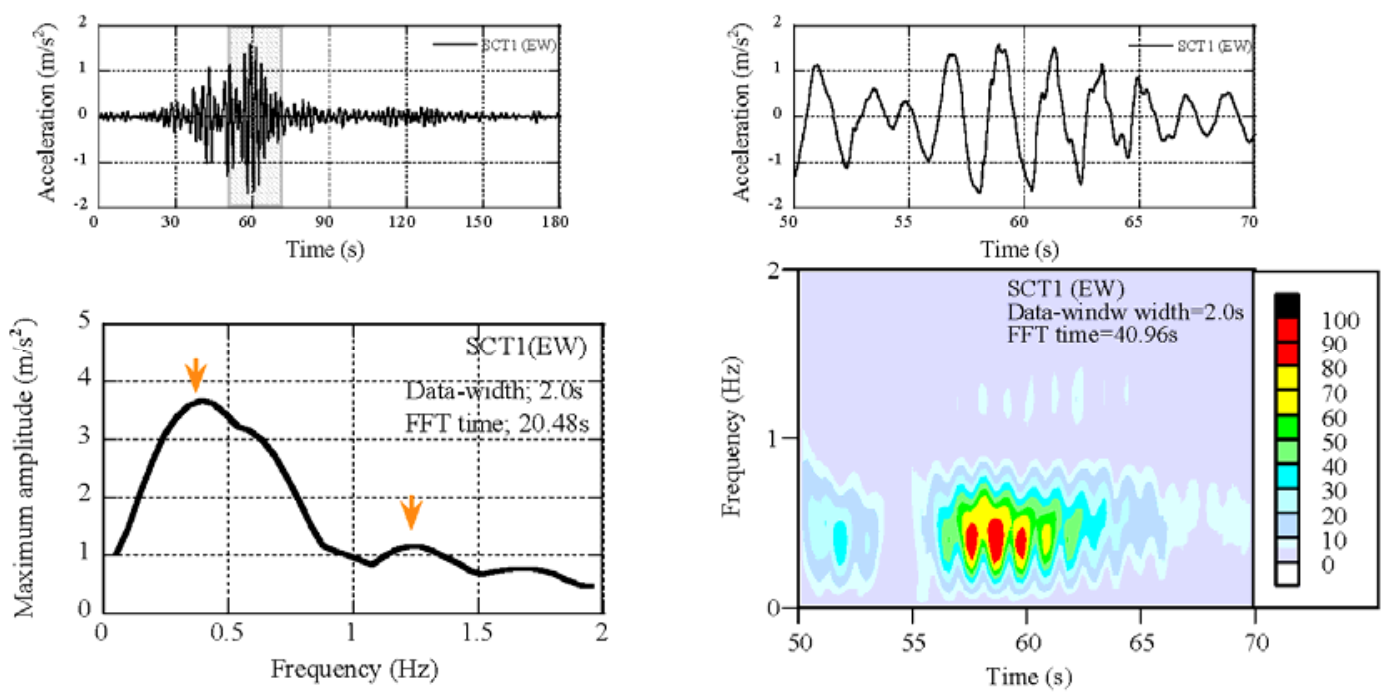

Fig.A2-2 Non-stationary Fourier spectra of SCT1 (EW) 
The property of the dominant components is evaluated as follows.

(1) The frequency-shift of dominant component is not observed.

(2) This dominant mode of three cycles from 55 to $65 \mathrm{~s}$ is considered as the stationary vibration.

(3) The predominant frequency component is $0.39 \mathrm{~Hz}$ with the amplitude of $3.6 \mathrm{~m} / \mathrm{s}^{2}$.

(4) The accompany frequency component is $1.2 \mathrm{~Hz}$ with the amplitude of $1.2 \mathrm{~m} / \mathrm{s}^{2}$. 